NASA Technical Memorandum 85797

NASA-TM-85797 19840025763

\title{
A REVIEW OF CHEVRON-NOTCHED FRACTURE SPECIMENS
}

J. C. NEWMAN, JR.

\section{FOR REFERENCE

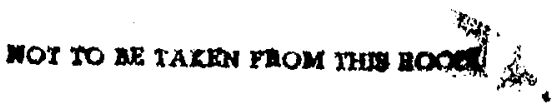

SEPTEMBER 1984

\section{UIBRARY COPY \\ or. 1 21984 \\ LANGLEY RESEARCH CENTER LIBRARY, NASA \\ HAMPTON, VIRGINIA}

\section{N/Sก}

National Aeronautics and Space Administration 



\section{A REVIEW OF CHFVRON-NOTCHED FRACTURE SPECIMENS}

J. C. Newman, Jr.

NASA Langley Research Center

Hampton, Virginia

\section{SUMMARY}

This paper reviews the historical development of chevron-notched fracture specimens; it also compares stress-intensity factors and load line displacement solutions that have been proposed for some of these specimens. The review covers the original bend-bar configurations up to the present day "short" rod and bar specimens. In particular, the results of a recent "analytical" round robin that was conducted by an ASTM Task Group on ChevronNotched specimens are presented.

In the round robin, three institutions calculated stress-intensity factors for either the chevron-notched round-rod or square-bar specimens. These analytical solutions were compared among themselves, and then among the various experimental solutions that have been proposed for these specimens. The experimental and analytical stress-intensity factor solutions that were obtained from the compliance method agreed within 3 percent for both specimens. An assessment of the consensus stress-intensity factor (compliance) solution for these specimens is made.

The stress-intensity factor solutions proposed for three- and four-point bend chevron-notched specimens are also reviewed. On the basis of this review, the bend-bar configurations need further experimental and analytical calibrations. 
The chevron-notched rod, bar, and bend-bar specimens were developed to determine fracture toughness of brittle materials, materials that exhibit "flat" or "nearly flat" crack-growth resistance curves. The problems associated with using such specimens for materials that have a rising crack-growth resistance curve are reviewed.

NOMENCLATURE

$A$

a

$\mathrm{a}_{0}$

$a_{1}$

b

B

$C^{\star}$

E

F

$F^{\star}$

$\mathrm{F}_{\mathrm{C}}^{\star}$

$\mathrm{F}_{\mathrm{m}}^{\star}$

$\mathrm{H}$

$\mathrm{K}$

$\mathrm{K}_{\mathrm{m}}$

K IC

K ICV

$\mathrm{K}_{\mathrm{R}}$ normalized stress-intensity factor defined by Barker

crack length measured from either front face of bend bar or load line

initial crack length (to tip of chevron notch)

crack length measured to where chevron notch intersects specimen surface

length of crack front

thickness of bar specimen or diameter of rod specimen

normalized compliance, $\mathrm{EBV}_{\mathrm{L}} / \mathrm{P}$, for chevron-notched specimen

Young's modulus of elasticity

normalized stress-intensity factor for straight-through crack specimen

normalized stress-intensity factor for chevron-notched specimen

normalized stress-intensity factor determined from compliance for chevron-notched specimen

minimum normalized stress-intensity factor for chevron-notched specimen

half of bar specimen height or radius of rod specimen

stress-intensity factor (Mode I)

minimum stress-intensity factor for chevron-notched specimen

plane-strain fracture toughness (ASTM E399)

plane-strain fracture toughness from chevron-notched specimen

crack-growth resistance 


$\begin{array}{ll}\mathrm{k} & \text { shear-correction parameter in Bluhm's slice model } \\ \mathrm{P} & \text { applied load } \\ \mathrm{P}_{\max } & \text { maximum test (failure) load } \\ \mathrm{V}_{\mathrm{L}} & \text { load-point half-displacement } \\ \mathrm{V}_{\mathrm{T}} & \text { half-displacement measured at top of specimen along load line } \\ \mathrm{w} & \text { specimen width } \\ \mathrm{x}, \mathrm{Y}, \mathrm{z} & \text { Cartesian coordinates } \\ \alpha & \text { crack-length-to-width }(\mathrm{a} / \mathrm{w}) \text { ratio } \\ \alpha_{i} & \text { crack-length-to-width }\left(\mathrm{a}_{\mathrm{i}} / \mathrm{w}\right) \text { ratios defined in Fig. } 2 \\ v & \text { Poisson's ratio }\end{array}$

\section{INTRODUCTION}

Chevron-notched specimens (Fig. 1) are gaining widespread use for fracture toughness testing of ceramics, rocks, high-strength. metals, and other brittle materials [1-7]. They are small (5- to 25-mm thick), simple, and inexpensive specimens for determining the plane-strain fracture toughness, denoted herein as $\mathrm{K}_{\mathrm{ICV}}$. Because they require no fatigue precracking, they are also well suited as quality control specimens. The unique features of a chevron-notched specimen, over conventional fracture toughness specimens, are: (1) the extremely high stress concentration at the tip of the chevron notch, and (2) the stress-intensity factor passes through a minimum as the crack grows. Because of the high-stress concentration factor at the tip of the chevron notch, a crack initiates at a low applied load, so costly precracking of the specimen is not needed. From the minimum stress-intensity factor, the fracture toughness can be evaluated from the maximum test load. Therefore, a load-displacement record, as is currently required in the ASTM E399 plane-strain fracture toughness $\left(K_{I C}\right)$ test procedure, is not needed. 
Because of these unique features, some of these specimens are being considered for standardization by the American Society for Testing and Materials (ASTM). This paper reviews the historical development of chevron-notched fracture specimens. The paper also compares the stress-intensity factor and load-line displacement solutions that have been proposed for some of these specimens. The review is presented in four parts.

In the first part, the review covers the development of the original chevron-notched bend bars, the present day "short" rod and bar specimens, and the early analyses for these specimens.

In the second part, the results of a recent "analytical" round robin conducted by the ASTM Task Group on Chevron-Notched Specimens are presented. Three institutions participated in the calculations of stress-intensity factors for either the chevron-notched round-rod or square-bar specimen. They used either three-dimensional finite-element or boundary-integral equation (boundary-element) methods. These analytical solutions were compared among themselves and among the various experimental solutions that have been determined for the rod and bar specimens. An assessment of the consensus stressintensity factor (compliance) solution for these specimens is presented. In the third part, some recent stress-intensity factor solutions, proposed for three- and four-point bend chevron-notched specimens, are reviewed. In the last part, the applicability of chevron-notched specimens to materials that have a rising crack-growth resistance curve is discussed. 


\section{HISTORY OF CHEVRON-NOTCHED SPECIMENS}

In 1964, Nakayama $[1,2]$ was the first to use a bend specimen with an unsymmetrical chevron notch. His specimen configuration is shown in Figure 1. He used it to measure fracture energy of brittle, polycrystalline, refractory materials. All previous methods which had been developed for testing homogeneous materials were thought to be inadequate. This specimen is unique in that a crack initiates at the tip of the chevron notch at a low load, then propagates stably until catastrophic fracture. Because of the low load, the elastic stored energy in the test specimen and testing apparatus was small so that the fracture energy could be estimated from the area under a load-time history record.

Tattersall and Tappin [3] in 1966 proposed using a bend bar with a chevron notch symmetrical about the center line of the specimen, as shown in Figure 1. They used this specimen to measure the work of fracture on ceramics, metals and other materials. The work of fracture was determined from the area under the load-displacement record divided by the area of the fracture surfaces.

In 1972, Pook [4] suggested using a chevron-notched bend bar to determine the plane-strain fracture toughness of metals. He stated that, "If the $\mathrm{K}_{\mathrm{I}}$ against crack length characteristic is modified, by the introduction of suitably profiled side grooves, so that there is a minimum at $a / w \approx 0.5$, and the initial $\mathrm{K}_{\mathrm{I}}$ is at least twice this minimum, it should be possible to omit the precracking stage, and obtain a reasonable estimate of $\mathrm{K}_{\mathrm{IC}}$ from the maximum load in a rising load test. Pook's "suitably profiled side grooves" is the present day chevron notch. However, he considered only the analytical treatment needed to obtain stress-intensity factors as a function of crack length for various types of chevron notches. He did not study the experimental aspects of using a chevron-notched specimen to obtain $\mathrm{K}_{\mathrm{IC}}{ }$ 
The nomenclature currently used for a straight-sided chevron notch in a rectangular cross section specimen is shown in Figure 2. The specimen width, $w$, and crack length, $a$, are measured from the front face of the bend bar (or from the load line in the knife-edge-loaded specimen). The dimensions a and $a_{1}$ are measured from the edge of the bend bar (or load line) to the vertex of the chevron and to where the chevron intersects the specimen surface, respectively. The specimen is of thickness $B$ and the crack front is of length $b$.

Pook [4] used the stress-intensity factor solution for a three-point bend bar with a straight-through crack [8] and a side-groove correction proposed by Freed and Kraft [9] to obtain approximate solutions for various shape chevron notches. The stress-intensity factors for a chevron-notched specimen, $K_{C N}$ was given by

$$
\mathrm{K}_{\mathrm{CN}}=\mathrm{K}_{\mathrm{STC}}\left(\frac{\mathrm{B}}{\mathrm{b}}\right)^{1 / 2}
$$

where $\mathrm{K}_{\mathrm{STC}}$ is the stress-intensity factor for a straight-through crack in a bar having the same overall dimensions. Figure 3 illustrates the unique stress-intensity factor solution for a chevron-notched specimen compared to a straight-through crack specimen. The dashed curve shows the normalized stress-intensity factors for the straight-through crack as a function of a/w. This curve is a monotonically increasing function with crack length. The solid curve shows the solution for the chevron-notched specimen. For $a=a_{0}$, the stress-intensity factor is very large but it rapidly drops as the crack length increases. A minimum value is reached when the crack length is between $a_{0}$ and $a_{1}$. For $a>a_{1}$, the stress-intensity factors for the chevron-notched specimen and for the straight-through crack specimen are identical because the configurations are identical. 
The analytical procedure used by Pook [4] to determine the stressintensity factor as a function of crack length was an engineering approximation. At that time, no rigorous analysis had been conducted to verify the accuracy of equation (1).

In 1975, Bluhm [10] made the first serious attempt to analyze the chevron-notched bend bars. The three-dimensional crack configuration was analyzed in an approximate "two-dimensional" fashion. The specimen was treated as a series of slices in the spanwise direction. Both beam bending and beam shear effects on the compliance of each slice were considered but the inter-slice shear stresses were neglected in the analysis. Then by a synthesis of the slice behavior, the total specimen compliance was determined. The slice model, however, introduced a "shear correction" parameter ( $k$ ) which had to be evaluated from experimental compliance measurements. Experimental compliance measurements made on an "uncracked" chevron-notched bend bar $\left(\alpha_{0}=0\right.$ and $\left.\alpha_{1}=1\right)$ were used to determine a value for the "shear correction" parameter for three- and four-point bend specimens. Bluhm estimated that the slice model was capable of predicting the compliance of the cracked Tattersali-Tappin type specimen (see Fig. 1) to within 3 percent. Bluhm did not, however, calculate stress-intensity factors from the compliance equations. Later, Munz et al. [7] did use Bluhm's slice model to calculate stress-intensity factors for various chevron-notch bar specimens.

In the following, the concept proposed by Pook [4] to determine the $K_{\text {Ic }}$ value for brittle materials using chevron-notched specimens will be illustrated. Figure 4 shows stress-intensity factor, $K$, plotted against crack length. The solid line beginning at $a_{0}$ and leveling off at $K_{I c}$ is the "ideal" crack-growth resistance curve for a brittle material. The dashed curves show the "crack-driving force" curves for various values of applied load on a chevron-notched specimen. Because of the extremely large $K$ value 
at $a=a_{0}$, a small value of load, like $P_{1}$, is enough to initiate a crack at the vertex of the chevron. At load $P_{1}$, the crack grows until the crack-drive value is equal to $K_{I C}$, that is, the intersection point between the dashed curve and horizontal line at point A. Further increases in load are required to extend the crack to point $B$ and $C$. When the maximum load, $P_{\max }$ is reached the crack-drive curve is tangent to the $K_{I c}$ line at point $D$. Thus, the $K$ value at failure is equal to $K_{I C}$. The tangent point also corresponds to the minimum value of stress-intensity factor on the crack-drive curve (denoted with a solid symbol). Therefore, $\mathrm{K}_{\mathrm{Icv}}$ is calculated by

$$
K_{I C V}=\frac{P_{\text {max }}}{B \sqrt{w}} F_{m}^{\star}
$$

where $P_{\max }$ is the maximum failure load and $F_{m}^{*}$ is the minimum value of the normalized stress-intensity factor. Because $\mathrm{F}_{\mathrm{m}}^{*}$ is a predetermined value for the particular chevron-notched configuration, it is necessary only to measure the maximum load to calculate $\mathrm{K}_{\mathrm{IcV}}$.

This maximum load test procedure can only be applied to brittle materials with flat or nearly flat crack-growth resistance curves. Many engineering materials, however, have a rising crack-growth resistance curve. The problems associated with using chevron-notched specimens for these materials will be discussed later.

\section{Chevron-Notched Rod and Bar Specimens}

Although the bend bars were the first type of chevron-notched specimens to be tested, the knife-edge loaded rod and bar specimens have received more attention. In the next sections, the rod and bar specimens are reviewed. This review also includes the analytical round robin; in which, the rod and bar specimens were analyzed. In a later section, some recent results on the chevron-notched bend bars are also reviewed. 
Barker $[5,6]$ in the late $70^{\prime} \mathrm{s}$, proposed the "short" rod and bar specimens, Figure 1, for determining plane-strain fracture toughness. These specimens are loaded by a knife-edge loading fixture $[5,7]$ resulting in an applied line load, $P$, at location $I$, as shown in Figure $5(a)$. Figure 5 shows the coordinate system used to define dimensions of the most commonly used rod and bar specimens. (Here the chevron notch intersects the specimen surface at $\mathrm{x}=\mathrm{w}$ or $\left.\alpha_{1}=1.\right)$

Rod Specimens.- Since 1977, the chevron-notched rod specimen, with $\mathrm{w} / \mathrm{B}=1.45$, has been studied extensively. Figure 6 shows a comparison of the minimum normalized stress-intensity factor as a function of the year the result was published. The open symbols denote the method by which the values were obtained. Each method will be discussed. The solid symbols show the results of corrections that have been made by the author.

In 1977, Barker [5] used the $K_{\text {IC }}$ value obtained from ASTM E399 compact specimens made of 2014-T651 aluminum alloy to determine the minimum stressintensity factor for the rod configuration by a "matching" procedure. The minimum stress-intensity factor was given by

$$
K_{m}=\frac{P_{\text {max }} A}{\sqrt{B^{3}\left(1-v^{2}\right)}}
$$

where $A$ is Barker's normalized stress-intensity factor that accounts for the configuration. By equating $K_{m}$ to $K_{I C^{\prime}}$ the value of $A$ was 20.8 . Equation (3) can be rewritten into the form

$$
K_{m}=\frac{P_{\max }}{B \sqrt{W}} F_{m}^{\star}
$$

where the value of $\mathrm{F}_{\mathrm{m}}^{*}$ is $26.3(\nu=0.3)$. (Equation (4) is the form commonly used for compact and knife-edge loaded specimens. The same form will be used herein.) Table 1 summarizes the minimum normalized stress-intensity factors 
obtained by various investigators; also listed are particular dimensions of the rod configuration used.

In 1979, Barker [11] replaced the term $\left(1-v^{2}\right)$ in equation (3) with unity without changing the value of $A$. Thus, the value of $F_{m}^{*}$ dropped by about 5 percent. The value of $\mathrm{F}_{\mathrm{m}}^{*}$ should have remained at 26.3 for $\nu=0.3$.

Barker and Baratta [12] in 1980 extensively evaluated the fracture toughness of several steel, aluminum, and titanium alloys using the rod specimen and $K_{I C}$ values measured according to ASTM Standard Method of Test for PlaneStrain Fracture Toughness of Metallic Materials (E399-78). They found that the critical stress-intensity factors, calculated from the rod specimen data using $F_{m}^{*}=25.5[12]$, were consistently low, averaging about 6 percent below the $K_{I C}$ values. They concluded that $\mathrm{F}_{\mathrm{m}}^{*}$ for the test configuration used in their study should be increased by 4 percent to a value of 26.5 .

Earlier, Barker and Guest [13] had conducted an experimental compliance calibration on the rod specimen and had obtained a value of $\mathrm{F}_{\mathrm{m}}^{*}$ as 29.6 . Their specimen, however, had $a \mathrm{w} / \mathrm{B}$ ratio of 1.474 [14]. Subsequently, the value of $F_{m}^{*}$ was corrected to a value corresponding to a w/B ratio of 1.45 by using a "constant moment" conversion described in reference 15 . The corrected value of $\mathrm{F}_{\mathrm{m}}^{\star} \quad(28.7)$ was about 3 percent lower than the compliance value from reference 13 , as indicated in Figure 6.

Beech and Ingraffea $[16,17]$ were the first to rigorously numerically analyze a chevron-notched specimen. They used a three-dimensional finiteelement method to determine stress-intensity factor distributions along the crack front and stress-intensity factors from compliance for the chevronnotched rod. The specimen they analyzed, however, differed from the proposed standard $\left(\mathrm{W} / \mathrm{B}=1.45 ; \alpha_{0}=0.332 ;\right.$ and $\left.\alpha_{1}=1\right)$ specimen analyzed in the ASTM round robin in three ways: (1) the load line was at the front face of the 
specimen rather than at $0.05 \mathrm{~B}$ into the specimen mouth, (2) the slot height (0.03B) was modelled (see Fig. $5(\mathrm{a})$ ) as zero, and (3) the square- or V-shaped cutout at the load line was not modelled. (The effects of these differences in specimen configuration on stress-intensity factors are discussed in reference 15 and will not be repeated here.) The stress-intensity factors reported in references 16 and 17 from their crack front evaluations were considerably lower ( 6 to 17 percent) than their values determined from a plane-strain compliance relation. They used their plane-strain compliance results to obtain a minimum stress-intensity factor. The value of $\mathrm{F}_{\mathrm{m}}^{*}$ from reference 17 was 4 percent higher than the value given in reference 16 . The difference in these results was due to the manner by which the compliance derivative was evaluated. The values of $F_{m}^{*}$ given in Table 1 were their plane-strain compliance values and, in parentheses, values obtained from a plane-stress compliance relation. The reason for using plane stress, herein, was that the displacements remote from the crack front are more nearly controlled by plane-stress conditions and, consequently, the plane-stress compliance relation would be more correct than using plane strain. (Also, all other results reported in Table 1, which were determined from compliance, were made with the plane-stress relation.) If the plane-strain compliance relation (with $\nu=0.3$ ) had been used, the $F_{m}^{*}$ values would have been about 5 percent higher than the plane-stress values (square and triangular symbols) shown in Figure 6.

Bubsey et al. [18], Shannon et al. [19], and Barker [15] used the experimental compliance (plane stress) relation to evaluate stress-intensity factors for the "short" rod specimen. Bubsey et al. and Shannon et al. used aluminum alloy specimens with $w / B$ ratios of $1.5,1.75$ and 2 for a wide range in $\alpha_{0}$. Their values in Table 1 and Figure 6 were interpolated for $\alpha_{0}=0.332$ 
and extrapolated to $w / B=1.45$ by using second degree polynominals in terms of $\alpha_{0}$ and $w / B$, respectively. Because the proposed standard dimensions are quite close to those used in the experiments, the interpolation and extrapolation procedure is expected to induce only a small error (probably less than 2 percent). Barker [15], on the other hand, used fused quartz $(v=0.17)$ on specimens with $w / B=1.45$. He reported a value of $A$ as 23.38, therefore, $\mathrm{F}_{\mathrm{m}}^{*}$ would be about 28.2 .

Raju and Newman [20], using a three-dimensional finite-element method, studied the effects of Poisson's ratio $(v)$ on stress-intensity factors for the rod specimen $(w / B=1.45)$. Their results indicated that a specimen with $\nu=0.17$ (fused quartz) would have a stress-intensity factor about 2 percent lower than a specimen with $v=0.3$ (aluminum alloy). Thus, if Barker [15] had used an aluminum alloy specimen, his experimental compliance value ( $F_{\mathrm{m}}^{*}$ ) would have been about 28.8 .

Raju and Newman [20] and Ingraffea et al. [21] determined the minimum stress-intensity factors for the rod specimen $(w / B=1.45)$ using compliance calculations from three-dimensional finite-element analyses. Each used the plane-stress compliance relation. Raju and Newman obtained a value of $F_{m}^{\star}$ as 28.4 (as plotted in Fig. 6) and Ingraffea et al. obtained a value of 28.3 (not plotted). The result from Raju and Newman, however, was estimated to be about 1.5 percent below the "true" solution based on a convergence study. Thus, the corrected value of $F_{m}^{\star}$ would have been about 28.8 .

Ingraffea et al. [21] also used a boundary-element (boundary-integral) method to determine the minimum stress-intensity factor from compliance. They obtained a value of $F_{m}^{*}$ as 28.3 (as plotted in Fig. 6), the same as from their finite-element analysis. The results from Ingraffea et al. [21] and Raju and Newman [20] were part of the analytical round robin, previously mentioned, and these results will be discussed and compared later. 
A comparison of minimum stress-intensity factors for the rod specimen $(w / B=1.45)$ shows several interesting features. First, the method of using $K_{I c}$ to determine $F_{m}^{*}$ gives results that are about 8 percent below experimental and analytical compliance methods. Although the specimen used by Barker [5,11] and Barker and Baratta [12] was somewhat different than the proposed standard specimen, these differences are not expected to be significant (see ref. 15, page 309). The specimens used in references 11 and 12 had chevron notches with curved sides instead of straight sides. Barker [14] argues that the calibration should be the same in a straight-sided and a curved-sided chevron-notch specimen, provided that the crack front length (b) and the rate of change in $b$ is the same in both specimens at the minimum stress-intensity factor. He determined that the $\alpha_{0}$ and $\alpha_{1}$ for an "equivalent" straight-sided chevron-notch specimen should be 0.343 and 0.992 , respectively. These values are quite close to those for the specimen analyzed in the ASTM round robin with straight-sided chevron notches. Therefore, at present, the 8-percent discrepancy in the values of $F_{m}^{*}$ cannot be explained from differences in specimen configuration.

One possible source of error in the $\mathrm{K}_{\mathrm{Ic}}$-matching procedure may be due to the different loads used in each test procedure. In the $K_{I c}$ test, the 5-percent secant offset load, $\mathrm{P}_{Q^{\prime}}$ is used to calculate $\mathrm{K}_{\mathrm{IC}}$. The $\mathrm{P}_{Q}$ load is always less than or equal to $\mathrm{P}_{\max }$, the maximum test (failure) load. Whereas, in the chevron-notch specimen test, the maximum load is always used to calculate $\mathrm{K}_{\mathrm{ICV}}$. For example, if $\mathrm{P}_{\max }$ was used to calculate $\mathrm{K}_{\mathrm{IC}}$ instead of $\mathrm{P}_{Q^{\prime}}$ then $\mathrm{K}_{\mathrm{IC}}$ would tend to be higher than the current value. Thus, the value of $F_{m}^{*}$ would also tend to be higher than the current value (circular symbols in Fig. 6). This would make the value of $F_{m^{\prime}}^{*}$ determined from the $\mathrm{K}_{\mathrm{Ic}}$-matching procedure, in closer agreement with the experimental and analytical compliance values shown in Figure 6. 
Second, the experimental $[13,15,18,19]$ and the recent analytical $[20,21]$ compliance determination of the minimum stress-intensity factor agree within about 3 percent of each other. Accounting for the fact that one of the analyses [20] was about 1.5 percent low, based on convergence studies, and that reference 15 used fused quartz, which has a low value of poisson's ratio so that a slightly lower value of $F_{m}^{\star}$ would be expected (about 2 percent), the agreement generally is within about 1 percent. Thus, for the rod specimen with $w / B=1.45, \alpha_{0}=0.332$, and $\alpha_{1}=1$ (straight-sided chevron) the value of $F_{\mathrm{m}}^{*}$ is estimated to be $28.9 \pm 0.3$. The dashed lines in Figure 6 show the expected error bounds on $\mathrm{F}_{\mathrm{m}}^{*}$.

Bar Specimens.- Two types of chevron-notched bar specimens have been studied. In 1978, Barker $[6,15]$ proposed a rectangular cross-sectioned bar specimen with an $\mathrm{H} / \mathrm{B}$ ratio of 0.435 (see Fig. 1). This specimen was designed in such a way that the same minimum stress-intensity factor was obtained as for his rod specimen [5]. However, because the early compliance calibration for the rod specimen was about 8 percent low (see Fig. 6), it was not clear whether the bar and rod specimens now have the same value. Raju and Newman [20] analyzed both specimens and found that the compliance calibration for the rectangular bar specimen was about 3.8 percent lower than the rod specimen.

In 1980, Munz et al. [7] proposed a square cross-sectioned bar specimen $(\mathrm{H} / \mathrm{B}=0.5)$. They conducted a very extensive experimental compliance calibration on bar specimens with $w / B=1.5$ and 2 for $\alpha_{0}$ ranging from 0.2 to 0.5 and $\alpha_{1}=1$. From these results, they obtained minimum values of stressintensity factors for each configuration considered. Using the assumption that the change of compliance with crack length in a chevron-notch specimen was the same as that for a straight-through crack specimen, they obtained an 
equation that was identical to equation (1) as

$$
F^{*}=F\left(\frac{\alpha_{1}-\alpha_{0}}{\alpha-\alpha_{0}}\right)^{1 / 2}=F\left(\frac{B}{b}\right)^{1 / 2}
$$

for $\alpha_{0}<\alpha<\alpha_{1}$. For specimens with an $\alpha_{0}$ of about 0.2 and 0.35 , the difference between experimental and analytical (eqn. (5)) minimum normalized stress-intensity factors was less than 1 percent. For an $\alpha_{0}$ value of about 0.5 , the difference was 3 to 3.5 percent. They concluded that equation (5) should only be used to obtain minimum values because experimental and analytical values differed greatly at small crack-length-to-width $(\alpha)$ ratios near $\alpha_{0}$.

Shannon et al. [19] have developed minimum stress-intensity factor expressions for chevron-notched bar (square) and rod specimens with $\alpha_{1}=1$ and $\alpha_{0}<0.5$. These expressions were fitted to minimum stress-intensity factors determined from experimental compliance measurements. For the squarebar specimen, the $\mathrm{w} / \mathrm{B}$ ratio was 1.5 or 2 and for the rod specimen, the w/B ratio was $1.5,1.75$ or 2 .

The use of chevron-notched specimens with materials that have a rising crack-growth resistance curve may require stress-intensity factors as a function of crack length instead of using only the minimum value. Recently, Shannon et al. [22] have developed polynomial expressions that give the stress-intensity factors and load-line displacements as a function of crack length for square-bar and rod specimens $\left(\alpha_{1}=1\right)$. These expressions were obtained from experimental compliance measurements made for various w/B ratios. The w/B ratio for the square-bar specimen was, again, 1.5 or 2 , and for the rod specimen was $1.5,1.75$, or 2 . The expressions apply to $\alpha_{0}$ between 0.2 and 0.4 , and $\alpha$ varying from $\alpha_{0}$ to 0.8 . Some of these results will be compared with the results from the ASTM analytical round robin in the next section. 
Analytical Round Robin on Chevron-Notched Rod and Bar Specimens In 1981, plans were formulated for a cooperative test and analysis program on chevron-notched square-bar and round-rod specimens by an ASTM task group on Chevron-Notched Specimen Testing. Four configurations were selected: the square and round versions of a relatively short specimen $(\mathrm{w} / \mathrm{B}=1.45) ;$ and the square and round versions of a longer specimen $(w / B=2)$. These configurations were chosen so as to include as many features as possible of prior work [5-7]. The coordinate system used to define the specimens is shown in Figure 5. The specimens were loaded by a knife-edge loading fixture that results in an applied load, $P$, at the load line $L$ in Figure 5(a). Specimens had either a square cutout [7] at the load line or a V-cutout [15] at the load line (not shown). The chevron notch, Figure 5(b), had straight sides and intersected the specimen sides at $x=w$ (or $\alpha_{1}=1$ ). The following table lists the dimensions of the specimens considered:

\begin{tabular}{llll}
\hline Specimen & $\mathrm{w} / \mathrm{B}$ & $\mathrm{a}_{0} / \mathrm{w}$ & $\mathrm{H} / \mathrm{B}$ \\
\hline Bar & 1.45 & 0.332 & 0.5 \\
Bar & 2 & 0.2 & 0.5 \\
Rod & 1.45 & 0.332 & 0.5 \\
Rod & 2 & 0.2 & 0.5 \\
\hline
\end{tabular}

The analysts were asked to calculate results for crack-length-to-width $(\mathrm{a} / \mathrm{w})$ ratios of $0.4,0.5,0.55,0.6$, and 0.7 . The information required from the analyses were:

(1) K-distribution as a function of $z$ and $a / w$ (see Fig. 5(b)).

(2) K-value from the plane-stress compliance relation as a function of $\mathrm{a} / \mathrm{w}$ : 


$$
K=\left[\frac{E P}{b} \frac{d V_{L}}{d a}\right]^{1 / 2}
$$

(3) Normalized displacements EVB/P at points $L$ and $T$ (see Fig. $5(a))$ as a function of $a / w$.

The participants in the round robin where:

\section{INVESTIGATORS}

A. R. Ingraffea, R. Perucchio, T. Y. Han, W. H. Gerstle, and $Y . P$. Huang
A. Mendelson and L. J. Ghosn
I. S. Raju and J. C. Newman, Jr.

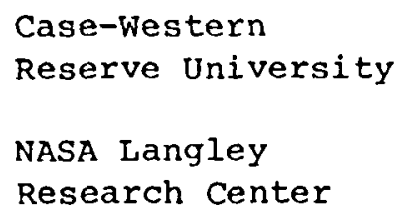

Case-Western

Reserve University

NASA Langley

Research Center

\section{INSTITUTION}

Cornell University

The following table lists the investigators, the three-dimensional method(s) used in the analyses, and the particular configuration(s) analyzed:

\begin{tabular}{|c|c|c|c|c|c|c|}
\hline \multirow[b]{2}{*}{ INVESTIGATORS } & \multirow[b]{2}{*}{ METHOD } & \multirow[b]{2}{*}{$w / B$} & \multicolumn{2}{|l|}{ ROD } & \multicolumn{2}{|l|}{ BAR } \\
\hline & & & 1.45 & 2 & 1.45 & $\overline{2}$ \\
\hline Ingraffea et al. [21] & $\begin{array}{l}\text { Finite-element } \\
\text { Boundary-element }\end{array}$ & & $\begin{array}{l}x \\
x\end{array}$ & & & \\
\hline $\begin{array}{l}\text { Mendelson and } \\
\text { Ghosn [23] }\end{array}$ & Boundary-element & & & & & $\mathrm{x}$ \\
\hline Raju and Newman [20] & Finite-element & & $\mathrm{x}$ & $\mathrm{x}$ & $\mathrm{x}$ & \\
\hline
\end{tabular}

All analyses were conducted on models of specimens with the square cutout at the load line, as shown in Figure 5(a). The slot height (0.03B) shown in Figure 5(a) was not modeled in any of the analyses (that is, the height was taken as zero).

Rod Specimen - Ingraffea et al. [21] and Raju and Newman [20] determined the distribution of normalized stress-intensity factors along the crack front of a rod specimen ( $\mathrm{w} / \mathrm{B}=1.45$ ) with $\alpha=0.55$ using boundary-element and finite-element methods, respectively. These results are compared in Figure 7 . 
The normalized stress-intensity factor $\left(F^{*}\right)$ is plotted against $2 z / b$. The center of the specimen is at $2 z / b=0$ and the crack intersects the chevron boundary at $2 z / b=1$, see insert. Ingraffea et al. used only one element, a quarter-point singular element, to define one-half of the crack front length (b/2); they showed a nearly linear distribution. On the other hand, Raju and Newman used five layers of singularity elements to define one-half of the crack front and they showed nearly constant stress-intensity factors for $2 z / b<0.5$. Their stress-intensity factors increased rapidly as $2 z / b$ approached unity. The results from Raju and Newnan were 0 to 16 percent higher than the results from Ingraffea et al. The difference is probably due to Ingraffea et al. using only one element along the crack front.

A comparison of experimental and analytical load-point displacements for the short chevron-notched $\operatorname{rod}(w / B=1.45)$ is shown in Figure 8 . The normalized displacement, $\mathrm{EBV}_{\mathrm{L}} / \mathrm{P}$, is plotted against a/w. Load-point displacements $\left(V_{L}\right)$ were either measured or calculated at $z=0$ (see Fig. 5(b)) as a function of crack length. Because the experiments and analyses were conducted on materials with different poisson ratios, the displacements have been adjusted, using results from Raju and Newman [20] on the Poisson effect, to displacements for a Poisson ratio of 0.3. Barker [15] measured load-point displacements on fused quartz $(\nu=0.17)$ using a laser-interferometric technique. His displacements have been reduced by 3 percent to compensate for the differences in Poisson ratios; his data are shown as circular symbols. In contrast, shannon et al. [22] measured displacements $\left(V_{T}\right)$ at the top of aluminum alloy $(v=0.3)$ specimens (see Fig. $5(a))$. They measured displacements for specimens with various values of $\alpha_{0}\left(0.2<\alpha_{0}<0.4\right)$ and with $w / B$ equal to $1.5,1.75$, and 2 . The results (square symbols) plotted in Figure 8 were interpolated to $\alpha_{0}=0.332$ and extrapolated to $\mathrm{w} / \mathrm{B}=1.45$, 
respectively, using second degree polynomials. These results agreed well with Barker's results.

Load-point displacements from Raju and Newman's finite-element analysis [20] and Ingraffea et al.'s [21] boundary-element analysis are also shown in Figure 8. The displacements from Ingraffea et al. have been reduced by 1 percent to compensate for a slight difference in Poisson's ratio. Both analytical results were from 4 to 6 percent below the experimental results. Based on beam theory [24], however, about 2 percent of this difference is caused by neglecting the notch $(0.03 B)$ made by a saw blade or chevron cutter (see Fig. 5(a)). These displacements were used by each investigator to determine the stress-intensity factors from the plane-stress compliance method. These results are described in the following section.

Experimental and analytical normalized stress-intensity factors ( $\left.F^{*}\right), a^{\prime}$ functions of $a / w$, for the chevron-notched rod are compared in Figure 9 . (Note the use of a broken scale.) The experimental and analytical results were obtained from the plane-stress compliance relation (eqn. (6)) as

$$
F_{C}^{*}=\frac{B \sqrt{w}}{P}\left[\frac{E P}{b} \frac{d V_{L}}{d a}\right]^{1 / 2}=\left[\left(\frac{1-\alpha_{0}}{\alpha-\alpha_{0}}\right) \frac{d C^{*}}{d \alpha}\right]^{1 / 2}
$$

where $C^{*}$ is the normalized compliance, $\mathrm{EBV}_{L} / \mathrm{P}$. The load-point displacement $\left(V_{L}\right)$ was either measured or calculated at $z=0$ as a function of crack length. Barker [15] measured the load-point displacements on fused quartz $(\nu=0.17)$ using a laser-interferometric technique. The displacements were then fitted to an empirical equation in terms of crack length. This equation was differentiated to obtain the compliance derivative. Barker's results are shown as circular symbols. Shannon et al. [22] measured displacements ( $V_{T}$ ) at the top of aluminum alloy $(\nu=0.3)$ specimens. They assumed that $\mathrm{dV}_{\mathrm{T}} / \mathrm{da}$ was 
equal to $\mathrm{dV}_{\mathrm{L}} / \mathrm{da}$ to obtain stress-intensity factors. Again, these results were interpolated and extrapolated to $\alpha=0.332$ and $w / B=1.45$ using second degree polynomials. Shannon's results (square symbols) are a few percent higher than Barker's results. As previously mentioned, Raju and Newman [20] have shown by a three-dimensional stress analysis that there is a slight difference (about 2 percent) between stress-intensity factors for $v=0.17$ and 0.3 ; these results agreed with the observed experimental differences.

The analytical results from Raju and Newman [20] and Ingraffea et al. [21] are also shown in Figure 9. Based on a convergence study [20], the analytical results are expected to lie about 1.5 percent below the "true" solution. The analytical results agreed well (within 3 percent) with the experimental results near the minimum value of $\mathrm{F}_{\mathrm{C}}^{*}$.

Figure 10 compares how analyses and test results $\left(F_{C}^{*}\right)$ vary with $a / w$ for the chevron-notched rod with $w / B=2$. The solid curve represents an equation proposed by Bubsey et al. [18] for the rod specimens. The equation they used was equation (5) where $F$ was the normalized stress-intensity factor for a straight-through crack in the same configuration [18].

Shannon et al.'s [22] results shown in Figure 10 were obtained from equation (7) using measured load-line displacements $\left(V_{T}\right)$ on the rod specimen. Their results agreed well (within 1 percent) with the equation from Bubsey et al., except at small values of $\alpha$. From previous work [7], it was recognized that equation (5) overestimates values of $F_{C}^{\star}$ for values of $\alpha$ approaching $\alpha_{0}$. The finite-element results of Raju and Newman [20] were about 2.5 percent below the results from Bubsey et al. and Shannon et al. Based on all of these results, the value of the minimum normalized stressintensity factor $\left(F_{m}^{*}\right)$ is estimated to be in the range $36.2 \pm 0.4$.

Bar Specimen.- Mendelson and Ghosn [23], using the boundary-element method, and Raju and Newman [20], using the finite-element method, determined 
the distribution of boundary-correction factors along the crack front of a bar specimen with $\mathrm{w} / \mathrm{B}=2$ and $\alpha=0.55$. The results are compared in Figure 11 . Here $\mathrm{F}^{*}$ is plotted against $2 z / \mathrm{b}$. Mendelson and Ghosn, in contrast to Ingraffea et al. [21], used five elements to define one-half of the crack front length. Their elements were assumed to have either linear tractions or linear displacements. They determined $F^{*}$ values by using either crack-surface displacements or normal stresses near the crack front. For $2 z / b<0.9$, their results were 3 to 16 percent higher than the results from Raju and Newman, whereas the previous results from Ingraffea et al., using the same (boundaryelement) method (Fig. 7), gave results on a rod specimen that were consistently lower than the results from reference 20. The reason for the discrepancy between references 20 and 23 on stress-intensity factor distributions is not clear.

Experimental and analytical load-point displacements at $z=0$ for the chevron-notched bar with $w / B=2$ are compared in Figure 12. Normalized displacement is plotted against a/w. Shannon et al. [22] measured displacements at the top of aluminum alloy specimens (circular symbols). The solid curve represents a polynomial equation from reference 22 that was fitted to the experimental data. The finite-element results from Raju and Newman [20], $v=0.3$, ranged from 3.5 to 6 percent lower than the experimental data. And the boundary-element results from Mendelson and Ghosn [23] were 8 to 11 percent lower than the experimental data. (Results from reference 23, $v=1 / 3$, were increased by 1 percent to compensate for the small difference in Poisson's ratio from $v=0.3$.$) Again, these displacements were used by each$ investigator to determine the stress-intensity factors from the plane-stress compliance method (eqn. (7)).

The normalized stress-intensity factors $\left(F_{C}^{\star}\right)$, as functions of $a / w$, for the bar specimen with $w / B=2$ are shown in Figure 13. The experimental 
results and polynomial equation of shannon et al. [22] are shown as circular symbols and solid curve, respectively. The dashed curve shows an equation proposed by Munz et al. [7] for bar specimens. For the chevron-notched specimen, Munz et al. used equation (5) where $F$ was the normalized stressintensity factor for a straight-through crack in the same configuration [7]. Again, equation (5) overestimates $F_{C}^{\star}$ for $\alpha$ approaching $\alpha_{0}$. But for larger values of $\alpha$, the equation underestimates $F_{C}^{\star}$ based, at least, on the present experimental results $[22]$.

The analytical results of Mendelson and Ghosn [23] and Raju and Newman [20] are also shown in Figure 13. Near the minimum $F_{C}^{*}$ value, the results from Mendelson and Ghosn were about 1.5 percent lower than the experimental results but overestimated $F_{C}^{\star}$ on either side of the minimum. The results from Raju and Newnan were about 2.5 percent lower than the experimental results. From all of the experimental and analytical results, the minimum $F_{m}^{*}$ is estimated to be $29.8 \pm 0.3$.

In Figure 14, experimental and analytical normalized stress-intensity factors, as functions of $a / w$, are compared for the bar specimen with $w / B=1.45$. The experimental results from Shannon et al. [22] were, again, obtained by interpolation and extrapolation to $\alpha_{0}=0.332$ and $w / B=1.45$ from results obtained from specimens with various $\alpha_{0}$ and $w / B$ ratios. The solid curve shows the equation proposed by Munz et al. [7]. Near the minimum $F_{C^{\prime}}^{*}$ the equation agreed well with the experimental results (within 1 percent) but, again, overestimated results for a/w ratios less than about 0.55. The analytical results from Raju and Newman [20] were 0 to 1.5 percent lower than the experimental results. The minimum value from Raju and Newman was 24.43, from Shannon et al, was 24.85, and from Munz et al, was 24.66 . From these results, the minimum value of $F_{m}^{*}$ is estimated to be $24.8 \pm 0.3$. 


\section{Chevron-Notched Bend Bars}

As previously mentioned, Nakayama [1,2], and Tattersall and Tappin [3] were the first to introduce and to determine fracture energies from chevronnotched bend bars. Pook [4] and Bluhm [10] were the first to provide approximate stress-intensity factors and compliance expressions, respectively, for these specimens. This section reviews the more recent experimental and analytical stress-intensity factor solutions that have been proposed for chevron-notched bend bars.

Munz et al. [25] compared stress-intensity factors for various four-point bend specimens with $0.12<\alpha_{0}<0.24,0.9<\alpha_{1}<1$, and $w / B=1$ or 1.25 . Two analytical methods were studied. The first was by the use of equation (7) wherein $\mathrm{dC} * / \mathrm{da}$, the compliance derivative of the chevron-notched specimen, was assumed to be equivalent to $\mathrm{dc} / \mathrm{d} \alpha$, the compliance derivative of a straight-through crack. Under this assumption, equation (7) reduces to equation (5) or Pook's equation [4]. The second method was by using Bluhm's slice model [10]. Bluhm's slice model is probably more accurate than Pook's equation, but neither method has been substantiated by experimental compliance measurements or by more rigorous analytical (three-dimensional elasticity) methods. The slice model was, however, calibrated to experimental compliance measurements made on uncracked chevron-notch bend bars. A comparison of the two analytical results showed that the differences ranged from -5 to 10 percent for the particular configurations considered.

In 1981, Shih [26] proposed a "standard" chevron-notched bend bar configuration for three-point loading with a major-span-to-width ratio (s/w) of 4. The $w / B$ ratio was 1.82 with $\alpha=0.3$ and $\alpha_{1}=0.6$. Shih [26] used the $K_{I C}$ value from 7079-T6 aluminum alloy and the failure (maximum) load on the chevron-notched bend bars to estimate the minimum stress-intensity factor; this value is shown in Figure 15 as the horizontal dashed line. The equation 
proposed by Pook [4] (upper solid curve) gave a minimum value very close to the value determined by Shih. Later, however, Shih [27] re-evaluated the minimum by testing 7079-T6 aluminum alloy compact specimens and chevronnotched specimens made from the same plate. The new $K_{I c}$ value dropped by 19 percent from the old value and, consequently, the minimum value $\left(F_{\mathrm{m}}^{*}\right)$ dropped to 10.17 , as shown by the dash-dot line in Figure 15 .

Wu [28] used equation (5) to determine the stress-intensity factors for three-point bend chevron-notched specimens. His equation gave essentially the same results (within 1 percent) as that shown for Pook in Figure 15. Wu [29] also used Bluhm's slice model to determine specimen compliance and then used equation (7) to determine $F_{C}^{*}$ as a function of $\alpha$ (or $a / w$ ). His equation was used herein to calculate $F_{C}^{*}$ in Figure 15. Here the minimum value from Wu's equation was about 4 percent higher than the new minimum values proposed by Shih [27]. From these results, it is obvious that Pook's equation and Bluhm's slice model give drastically different values of stress-intensity factors, and that the determination of minimum values by matching $\mathrm{K}_{\mathrm{Ic}}$ and $\mathrm{K}_{\mathrm{m}}$ must be approached with caution.

\section{EFFECTS OF MATERIAL FRACTURE TOUGHNESS BEHAVIOR}

For a brittle material, a material which exhibits a "flat" crack-growth resistance curve as shown in Figure 4 , the use of a chevron-notched specimen to obtain $K_{I C V}$ is well justified. But what if the material has a "rising" crack-growth resistance curve as shown in Figure 16? Because most engineering materials, under non-plane-strain conditions, have rising crack-growth resistance curves or $\mathrm{K}_{\mathrm{R}}$-curves, the answer to this question is of utmost importance. The objective of this paper, however, is not to answer this question, but to review some of the problems associated with using these specimens for such materials. 
Figure 16 illustrates the application of the $K_{R}$-curve concept [30] to a material with a rising $\mathrm{K}_{\mathrm{R}}$-curve. The stress-intensity factor is plotted against crack length. The hypothetical $\mathrm{K}_{\mathrm{R}}$-curve (solid curve) begins at the initial crack length, $\alpha_{0}$. The dashed curves show the "crack-driving force" curves for various values of applied load on a chevron-notched specimen $(w=$ constant $)$. As the load is increased, the crack grows stably into the material (point $A$, to $B$, to $C$, to $D$ ) until the load reaches $P_{\max }$. At this load and crack length, crack growth becomes unstable (point D). As can be seen, the instability point (tangent point between crack-drive curve and $K_{R}$-curve) does not correspond to the minimum $K$ value (solid symbol). Consequently, the maximum load and minimum $\mathrm{K}$ value cannot be used to compute the stress-intensity factor at failure, although the difference might be small. But if the specimen width is smaller than that used in Figure 16, then the instability point would occur at a lower point on the $\mathrm{K}_{\mathrm{R}}$-curve. Conversely, the instability point for a larger width specimen would occur at a higher point on the $K_{R}$-curve. Thus, a specimen size (or width) effect exists and it has been the subject of several papers on chevron-notched specimens $[12,31-35]$ 


\section{DISCUSSION}

\section{Chevron-Notched Test Specimens}

Many investigators have shown the advantages of using chevron-notched specimens for determination of plane-strain fracture toughness of brittle materials. The following table summarizes some of the advantages and disadvantages of these specimens:

ADVANTAGES

- smatl specimens

- NO FAtigue PRECRACKING

- simple test pRoceduRE

- maximum load test

- SCREENING TEST

- NOTCh GUIDES CRACK PATh

- high CONSTRAINT AT CRACK FRONT

\section{DISADVANTAGES}

- RESTRICTED to "BRITtLE" MAterials

- material thickness limitations

- NOTCH MACHINING DIFFICULTY

The chevron-notched specimens can be small because their width and height are of nearly the same size as their thickness $(5$ to $25 \mathrm{~mm})$, so only a small amount of material is needed. Consequently, they are very useful as quality control specimens. They may be useful in alloy development programs where small amounts of material are produced. They can also be used to determine toughness profiles through the thicknesses of large plates. Because they require no fatigue precracking, they cost less than current fracture toughness specimens. For brittle materials, the test procedure is very simple; once the minimum stress-intensity factor has been obtained, it is only necessary to record the maximum failure load to calculate fracture toughness. Even for ductile materials, the specimens may be used in screening tests to rank materials.

The chevron notch tends to guide the crack path and, therefore, these specimens can be used to test particular regions of a material, such as 
heat-affected zones. The notch also constrains the crack front, which helps set up an approximate plane-strain condition around the crack front.

The major disadvantage in using chevron-notched specimens with the maximum load test procedure - for plane-strain fracture toughness testing - is that they are restricted to brittle materials, such as ceramics, rocks, highstrength metals, and other low toughness materials. Further studies are needed on more ductile materials to see if these specimens can be used for fracture toughness evaluation. They are also limited in the thickness that can be tested. Thin materials, less than about $5 \mathrm{~mm}$, cannot be easily tested.

\section{Stress-Intensity Factors}

Several methods have been used to determine stress-intensity factors and minimum stress-intensity factors for these specimens. In the first method, the minimum value was obtained by matching $K_{m}$ to $K_{I C}$ from ASTM E399 standard specimens. For the "short" rod specimen, the minimum value obtained from $K_{I C}$-matching $[5,11,12]$ was about 8 percent below several experimental compliance calibrations and two recent three-dimensional elasticity solutions. In more recent applications of the $K_{I C}$-matching procedure $[26,27]$, the minimum values for a three-point bend specimen differed by about 20 percent. Thus, the $\mathrm{K}_{\mathrm{Ic}}$-matching procedure should be used with caution.

The second method is derived from the assumption that the change in compliance with crack length of the chevron-notch specimen is equal to the change in compliance of a straight-through crack specimen. The stress-intensity factors derived from this method match those from Pook's equation [4]. For the rod and bar specimens, researchers have shown that this method gives accurate values of minimum stress-intensity factors, but is unreliable on either side of the minimum. In contrast, this method gave very large differences on a threepoint bend specimen. Again, this method must be used with caution. 
The third, a more refined approximate method for chevron-notched specimens, is the slice model proposed by Bluhm [10]. This model has been used extensively on three- and four-point (chevron-notched) bend specimens. Munz et al. [7] has used this model on chevron-notched bar specimens. The problem associated with this method is the "shear-correction" parameter ( $k$ ) that must be determined from experimental compliance measurements. If the shear-correction parameter, $k$, is determined experimentally from uncracked chevron-notched specimens close to the desired configuration, then this method will probably give reliable results. But a systematic study to evaluate the accuracy of stress-intensity factors computed from the slice model has not been undertaken.

The fourth method is three-dimensional elasticity solutions, such as finite-element and boundary-integral equation methods. These methods can give accurate stress-intensity factors if care is taken especially in conducting convergence studies. These methods, however, tend to be expensive if a large number of solutions are desired.

The last method is expeximental compliance calibration. This method can also give accurate stress-intensity factors if the tests are done carefully. But the method is limited to the particular specimen configurations studied. Coupled with Bluhm's slice model, this method may provide a reliable and inexpensive way of obtaining stress-intensity factors for a wide range of configuration parameters.

A summary of the consensus minimum normalized stress-intensity factor, $\mathrm{F}_{\mathrm{m}}^{*}$, for the four configurations considered in the analytical round robin and for the rectangular bar specimen $[6,15,20]$ are shown in the following table. 


\begin{tabular}{llllll}
\hline Specimen & W/B & \multicolumn{1}{c}{$\alpha_{0}$} & $\alpha_{1}$ & H/B & $F_{\mathrm{m}}^{*}$ \\
\hline Bar & 1.45 & 0.332 & 1 & 0.435 & $27.8 \pm 0.3$ \\
Bar & 1.45 & 0.332 & 1 & 0.5 & $24.8 \pm 0.3$ \\
Bar & 2 & 0.2 & 1 & 0.5 & $29.8 \pm 0.3$ \\
Rod & 1.45 & 0.332 & 1 & 0.5 & $28.9 \pm 0.3$ \\
Rod & 2 & 0.2 & 1 & 0.5 & $36.2 \pm 0.4$ \\
\hline
\end{tabular}

The stress-intensity factor solutions for three- and four-point bend chevron-notched specimens have only been obtained from the $\mathrm{K}_{\mathrm{IC}}$-matching procedure, Pook's equation, and Bluhm's slice model. Of these, the slice model is probably the most reliable. However, it is recommended that a detailed finite-element or boundary-element analysis, or careful experimental compliance calibrations, be performed on various chevron-notched bend bar configurations.

\section{CONCLUSIONS}

The historical development of chevron-notched fracture specimens and the stress-intensity solutions that have been proposed for these specimens was reviewed. The review covered the three- and four-point bend bars as well as the "short" rod and bar specimens. The stress-intensity factor solutions and minimum stress-intensity value for these specimens had been obtained by using several different methods, either experimental or analytical. Results of a recent ASTM analytical round robin on the rod and bar specimens were summarized. Some problems associated with using these specimens for materials with rising crack-growth resistance curves were discussed. Based on this review, the following conclusions were drawn: 
1. For the chevron-notched round-rod and bar specimens, the experimental compliance calibrations and the analytical (finite-element, boundary-element, and some approximate methods) calculations agreed within 3 percent. When the lower bound convergence of the finiteelement and boundary-element techniques were accounted for, the agreement was generally within about 1 percent.

2. Chevron-notched bend bars need further experimental and analytical stress-intensity factor calibrations. Although some recent stressintensity factor solutions agreed within 5 percent, they were obtained from methods which have not been adequately substantiated.

3. Further studies are needed on using chevron-notched specimens with materials that exhibit a "rising" crack-growth resistance curve behavior. 


\section{REFERFNCES}

[1] Nakayama, J.: A Bending Method for Direct Measurement of Fracture Energy of Brittle Material, Japan Journal of Applied Physics, Vol. 3, 1964, pp. 422-423.

[2] Nakayama, J.: Direct Measurement of Fracture Energies of Brittle Heterogeneous Materials, Journal of the American Ceramic Society, Vol. 43, No. 11, Nov. 1965, pp. 583-587.

[3] Tattersall, H. G. and Tappin, G.: The work of Fracture and Its Measurement in Metals, Ceramics and Other Materials, Journal of Materials Science Vol. 1, 1966, pp. 296-301.

[4] Pook, I. P.: An Approach to a quality Control KIc Testpiece, International Journal of Fracture Mechanics, Vol. 8, 1972, pp. 103-108.

[5] Barker, L. M.: A Simplified Method for Measuring Plane Strain Fracture Toughness, Engineering Fracture Mechanics, Vol. 9, 1977, pp. 361-369.

[6] Barker, L. M.: Short Bar Specimens for KIC Measurements, Fracture Mechanics Applied to Brittle Materials, ASTM STP 678, American Society for Testing and Materials, Philadelphia, PA, 1979, pp. 73-82. (Proceedings Eleventh National Symposium Fracture Mechanics, Blacksburg, VA, June 1978.)

[7] Munz, D.; Bubsey, R. T.; and Srawley, J. E.: Compliance and StressIntensity Coefficients for short Bar Specimens with Chevron Notches, International Journal of Fracture, Vol. 16, No. 4, 1980, pp. 359-374.

[8] Brown, W. F. and srawley, J. E.: Plane strain Crack Toughness Testing of High Strength Metallic Materials, ASTM STP 410, American Society for Testing and Materials, Philadelphia, 1966. 
[9] Freed, C. N. and Kraft, J. M.: Effect of Side Grooving on Measurements of Plane-strain Fracture Toughness, Journal of Materials, Vol. 1, No. 4,1966, pp. $770-790$.

[10] Bluhm, J. I.: Slice Synthesis of a Three-Dimensional "Work of Fracture" Specimen, Engineering Fracture Mechanics, Vol. 7, 1975, pp. 593-604.

[11] Barker, L. M.: Theory for Determining $K_{I C}$ from Small, Non-LEFM Specimens, Supported by Experiments on Aluminum, International Journal of Fracture, Vol. 15, No. 6, 1979, pp. 515-536.

[12] Barker, L. M. and Baratta, F. I.: Comparisons of Fracture Toughness Measurements by the Short Rod and ASTM Standard Method of Test for Plane-Strain Fracture Toughness of Metallic Materials (E399-78), Journal of Testing and Evaluation, Vol. 8, No. 3, 1980, pp. 97-102.

[13] Barker, L. M. and Guest, R. V.: Compliance Calibration of the short Rod Fracture Toughness Specimen, Terra Tek Report TR 78-20, April 1978.

[14] Barker, L. M.: Discussion of "Compliance Calibration of the short Rod Chevron-Notch Specimen for Fracture Toughness Testing of Brittle Materials", by Bubsey, R. T.; Munz, D.; Pierce, W. S.; and Shannon, J. L., Jr., International Journal of Fracture, Vol. 19, 1982, pp. R3-R5 .

[15] Barker, L. M.: Compliance Calibration of a Family of short Rod and Short Bar Fracture Toughness Specimens, Engineering Fracture Mechanics, Vol. 17, No. 4, 1983, pp. 289-312.

[16] Beech, J. F. and Ingraffea, A. R.: Three-Dimensional Finite Element Calibration of the Short-Rod Specimen, Geotechnical Fngineering Report 80-3, Cornell University, 1980.

[17] Beech, J. F. and Ingraffea, A. R.: Three-Dimensional Finite Element Calibration of the Short-Rod specimen, International Journal of Fracture, vol. 18, No. 3, 1982, pp. 217-229. 
[18] Bubsey, R. T.; Munz, D.; Pierce, W. S. and Shannon, J. L., Jr.: Compliance of the Short Rod Chevron-Notch Specimen for Fracture Toughness Testing of Brittle Materials, International Journal of Fracture, Vol. 18, No. 2, 1982, pp. 125-133.

[19] Shannon, J. L., Jr.; Bubsey, R. T.; Pierce, W. S.; and Munz, D.: Extended Range Stress Intensity Factor Expressions for Chevron-Notched Short Bar and Short Rod Fracture Toughness Specimens, International Journal of Fracture, Vol. 19, 1982, pp. R55-R58.

[20] Raju, I. S. and Newman, J. C., Jr.: Three-Dimensional Finite-Element Analysis of the Chevron-Notched Fracture Specimens, symposium on Chevron-Notched Specimen: Testing and Stress Analysis, April 21, 1983, Louisville, KY.

[21] Ingraffea, A. R.; Perucchio, R॰; Han, T. Y.; Gerstle, W. H. and Huang, Y. P.: Three-Dimensional Finite and Boundary Element Calibration of the Short-Rod Specimen, Symposium on Chevron-Notched Specimens: Testing and Stress Analysis, April 21, 1983, Louisville, KY.

[22] Shannon, J. L., Jr.; Bubsey, R. T. and Pierce, W. S.: Closed-Form Expressions for Crack-Mouth Displacements and Stress-Intensity Factors for Chevron-Notched Short Bar and Rod Specimens Based on Experimental Compliance Measurements, NASA Lewis Research Center, NASA TM 83796, 1984.

[23] Mendelson, A. and Ghosen, L. J.: Three-Dimensional Analysis of Short Bar Chevron-Notched Specimens by Boundary Integral Method, Symposium on Chevron-Notched Specimens: Testing and Stress Analysis, April 21, 1983, Louisville, KY.

[24] Timoshenko, S. and Goodier, J. N.: Theory of Elasticity, second edition, MCGraw-Hill Book Co., New York, 1951. 
[25] Munz, D. G.; Shannon, J. L., Jr. and Bubsey, R. T.: Fracture Toughness Calculation from Maximum Load in Four Point Bend Tests of ChevronNotch Specimens, International Journal of Fracture, Vol. 16, 1980, R1 37-R141.

[26] Shih, T. T.: Chevron V-Notched Bend Specimen for $K_{I C}$ Measurement of Brittle Materials, Journal of Testing and Evaluation, Vol. 9, No. 1, 1981, pp. $50-55$.

[27] Shih, T. T.: An Evaluation of the Chevron V-Notched Bend Bar Fracture Toughness Specimen, Engineering Fracture Mechanics, Vol. 14, No. 4, 1981 , pp. $821-832$.

[28] Wu, Shang-Xian: An Investigation of Chevron-Notch Three-Point Bend Fracture Toughness Specimen, International Journal of Fracture, Vol. 19, 1982, pp. R27-R30.

[29] Wu, Shang-Xian: Compliance and Stress-Intensity Factor of ChevronNotched Three-Point Bend Specimen, Symposium on Chevron-Notched Specimens: Testing and Stress Analysis, April 21, 1983, Louisville, KY.

[30] Fracture Toughness Evaluation by R-Curve Method, ASTM STP 527, ed. by D. E. McCabe, American Society for Testing and Materials, Philadelphia, PA, 1973.

[31] Munz, D.; Bubsey, R. T. and Shannon, J. L., Jr.: Performance of Chevron-Notch Short Bar Specimen in Determining the Fracture Toughness of Silicon Nitride and Aluminum oxide, Journal of Testing and Evaluation, Vol. 8, No. 3, 1980, pp. 103-107.

[32] Munz, D.: Determination of Fracture Toughness of High Strength Aluminum Alloys with Chevron-Notched Short Rod and Short Bar Specimens, Engineering Fracture Mechanics, Vol. 15, No. 1-2, 1981, pp. 231-236. 
[33] Munz, D.; Himsolt, G.; and Eschweiler, J.: Effect of Stable Crack Growth on Fracture Toughness Determination for Hot-Pressed Silicon Nitride at Elevated Temperatures, Fracture Mechanics Methods for Ceramics, Rocks, and Concrete, ASTM STP 745, S. W. Freiman and E. R. Fuller, Eds., American Society for Testing and Materials, 1981, pp. 69-84.

[34] Barker, I. M.: Specimen Size Effects in Short Rod Fracture Toughness Measurements, Symposium on Chevron-Notched Specimen: Testing and Stress Analysis, April 21, 1983, Louisville, KY.

[35] Shannon, J. L., Jr. and Munz, D. G.: Specimen Size and Geometry Effects on Fracture Toughness of $\mathrm{Al}_{2} \mathrm{O}_{3}$ Measured with Short Rod and Short Bar Chevron-Notched Specimens, Symposium on ChevronNotched Specimens: Testing and Stress Analysis, April 21, 1983, Louisville, KY. 
Table 1.- Chronological development of minimum normalized stress-intensity factors $\left(\mathrm{F}_{\mathrm{m}}^{*}\right)$ for short chevron-notched rod

\begin{tabular}{|c|c|c|c|c|c|c|}
\hline Investigator(s) & Year & Ref. & $w / B$ & $a_{0} / w$ & $a_{1} / w$ & $F_{m}^{*}$ \\
\hline Barker ${ }^{a}$ & 1977 & 5 & 1.45 & $0.31^{b}$ & $0.96^{\mathrm{b}}$ & 26.3 \\
\hline Barker and Guest ${ }^{c}$ & 1978 & 13,14 & 1.474 & $0.343^{d}$ & $0.992^{\mathrm{d}}$ & 29.6 \\
\hline Barker & 1979 & 11 & 1.45 & $0.31^{b}$ & $0.96^{b}$ & 25.1 \\
\hline Barker and Baratta ${ }^{a}$ & 1980 & 12 & 1.45 & $0.343^{d}$ & $0.992^{\mathrm{d}}$ & 26.5 \\
\hline Beech and Ingraffea ${ }^{e}$ & 1980 & 16 & 1.5 & 0.35 & 1.0 & $31.4(30.0)^{f}$ \\
\hline Beech and Ingraffea & 1982 & 17 & 1.5 & 0.35 & 1.0 & $32.7(31.2)^{\mathrm{f}}$ \\
\hline Bubsey et al. ${ }^{c}$ & 1982 & 18 & 1.45 & 0.332 & 1.0 & 29.0 \\
\hline Barker $^{c}$ & 1983 & 15 & 1.45 & 0.332 & 1.0 & 28.2 \\
\hline Shannon et al. ${ }^{c}$ & 1983 & 22 & 1.45 & 0.332 & 1.0 & 29.1 \\
\hline Raju and Newman ${ }^{e}$ & 1983 & 20 & 1.45 & 0.332 & 1.0 & 28.4 \\
\hline Ingraffea et al. ${ }^{e, g}$ & 1983 & 21 & 1.45 & 0.332 & 1.0 & 28.3 \\
\hline
\end{tabular}

$a_{F_{m}^{*}}^{*}$ determined from matching $K_{I C}$ from ASTM E399 specimens.



$c_{F_{m}^{\star}}$ determined from experimental compliance.

${ }^{2}$ Curved-sided chevron notch used in test, equivalent dimensions for straight-sided chevron notch used for table.

$e_{F_{m}^{*}}$ determined from finite-element analysis and compliance.

$\mathrm{f}_{\mathrm{V}}$ alues are from plane-strain (plane-stress) assumption.

${ }^{g_{m}}$ determined from boundary-element analysis and compliance. 



$\underline{w}$
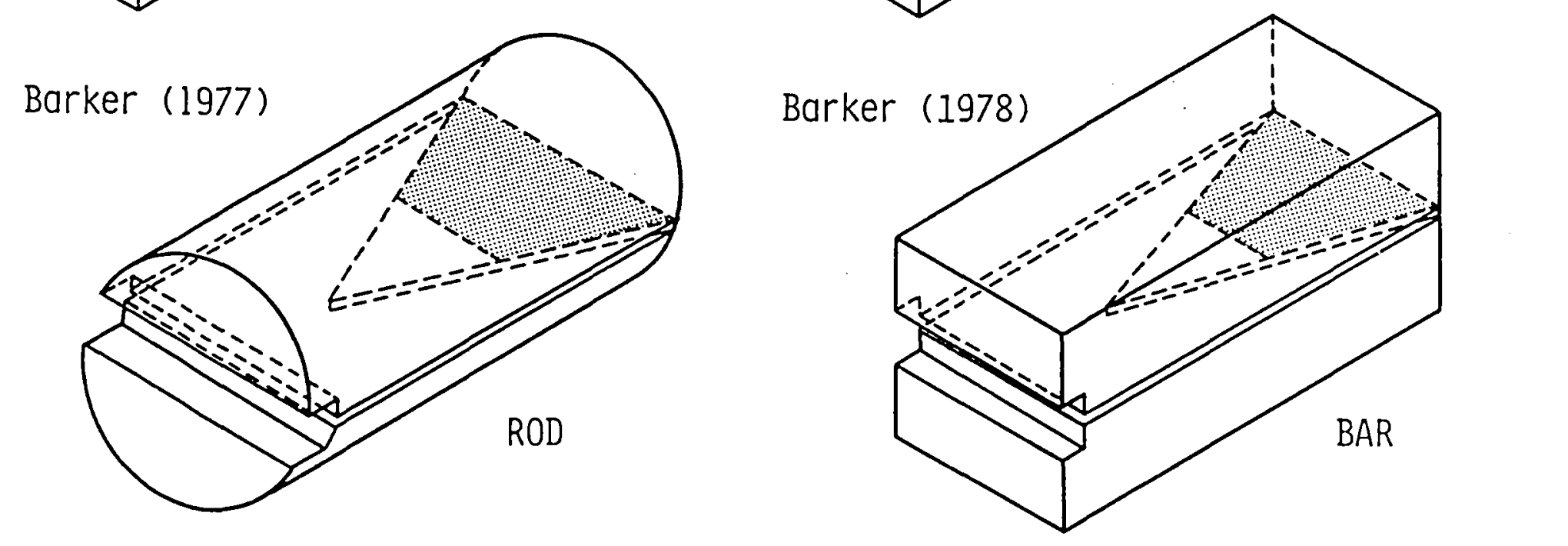

Figure 1.- Various chevron-notched fracture specimen configurations. 


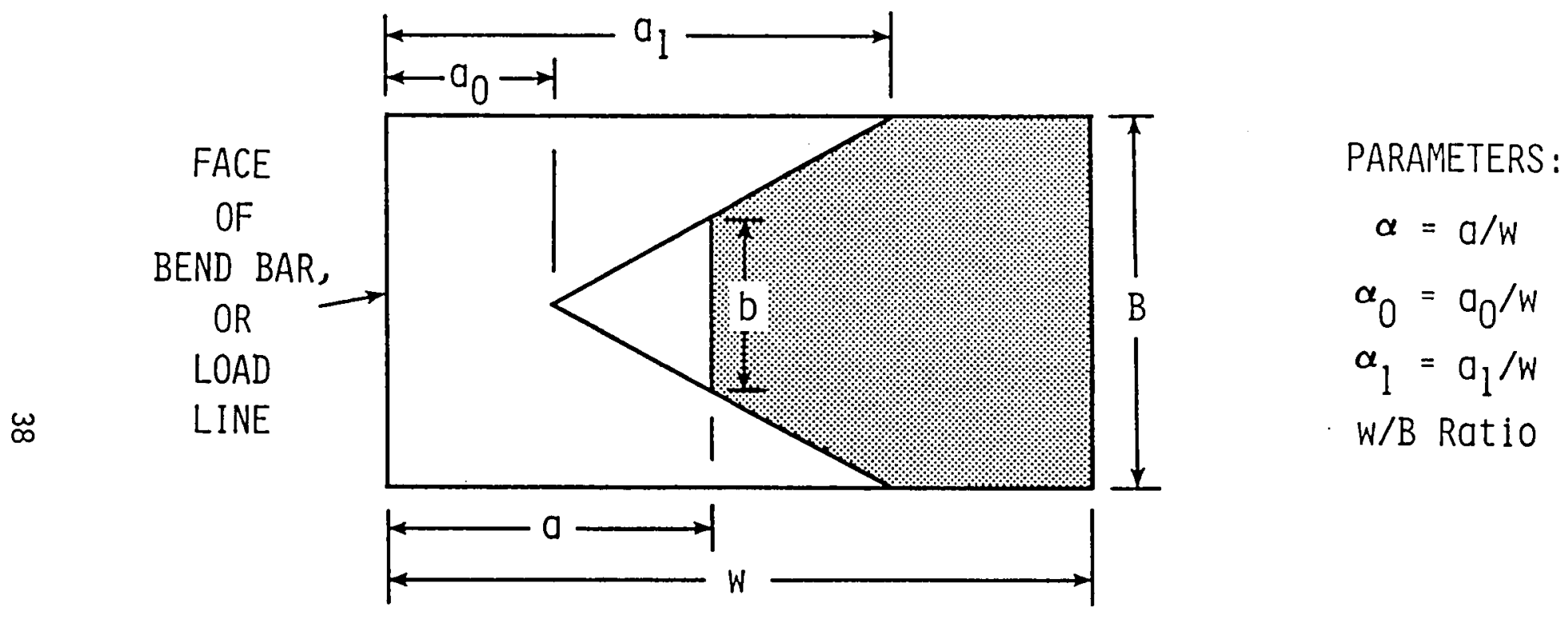

Figure 2.- Chevron-notched fracture specimen nomenclature. 


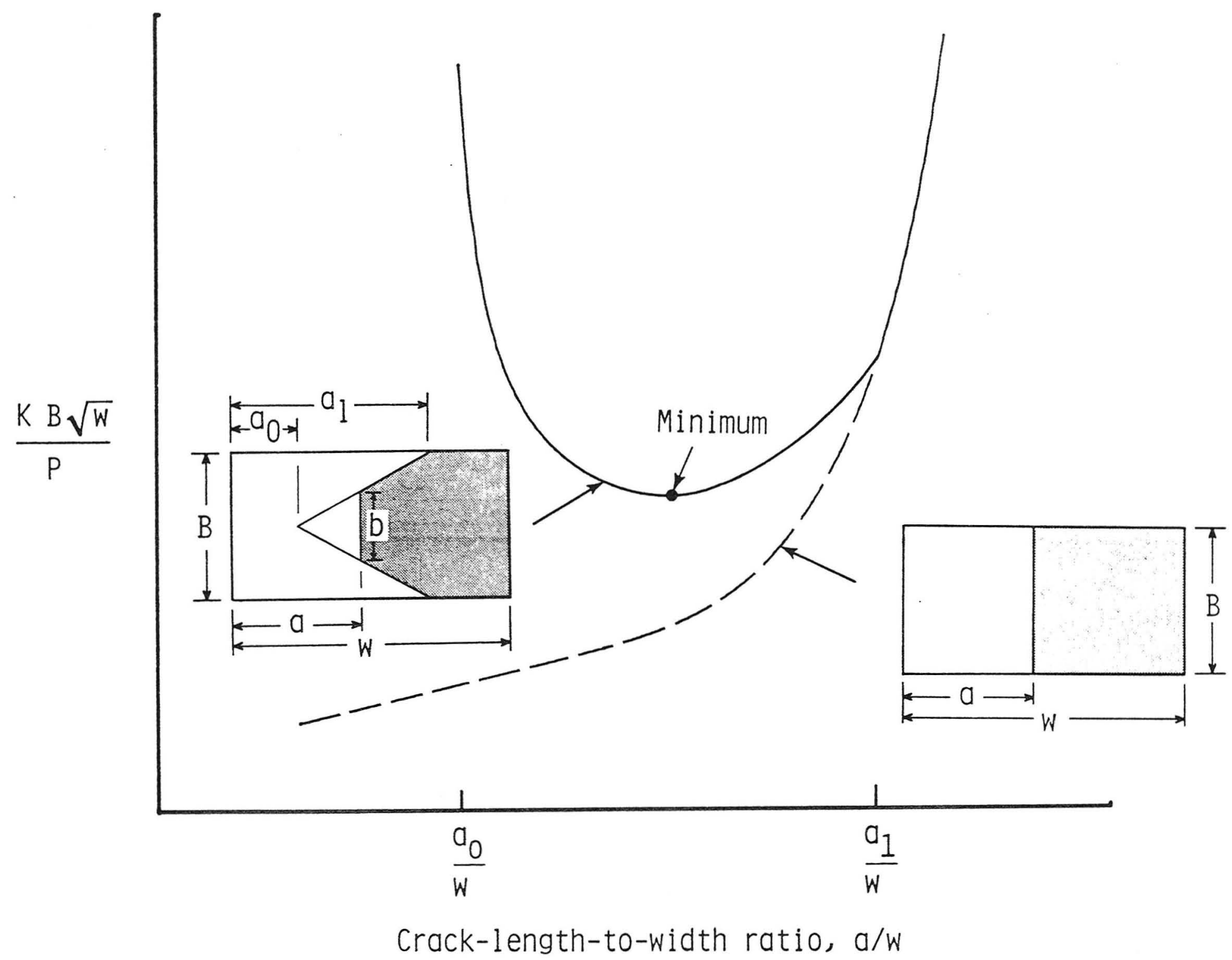

Figure 3.- Comparison of normalized stress-intensity factors for chevron-notched and straight-through crack specimens. 


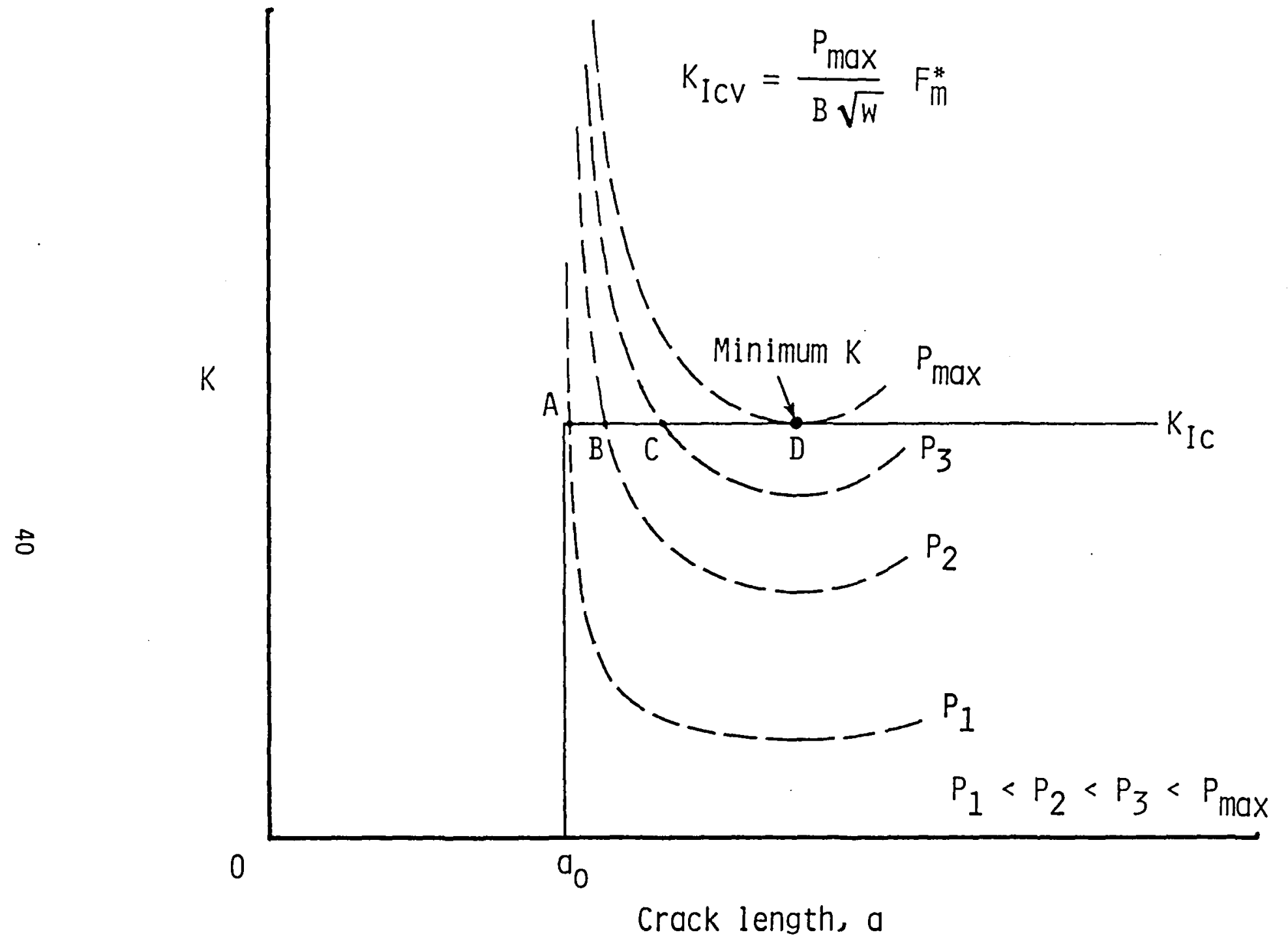

Figure 4.- Fracture of "brittle" material using a chevron-notched specimen. 


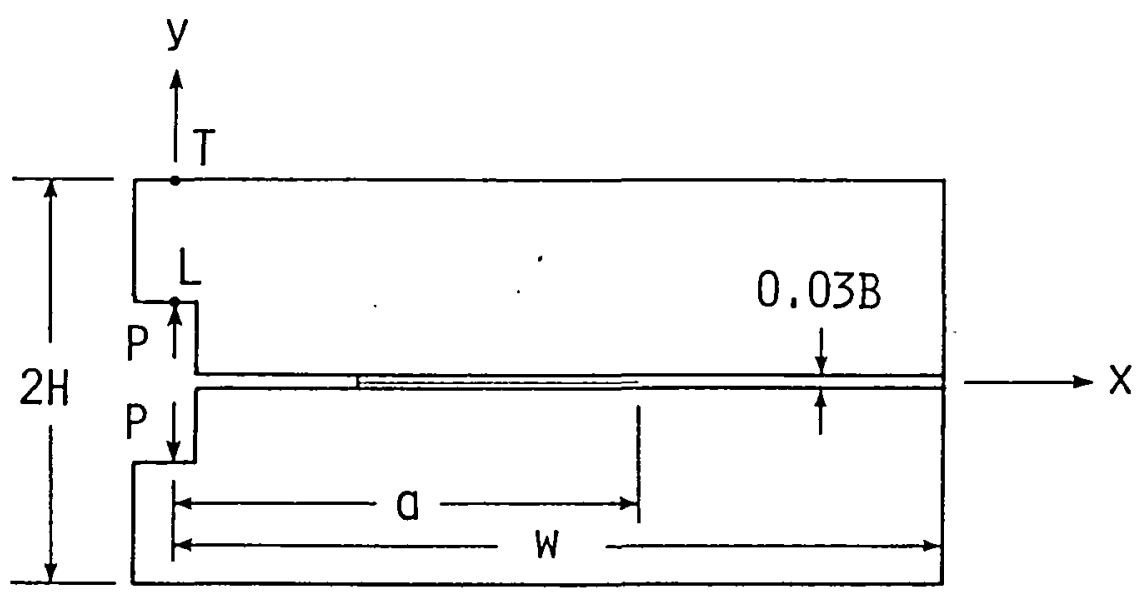

(a) $z=0$ plane,

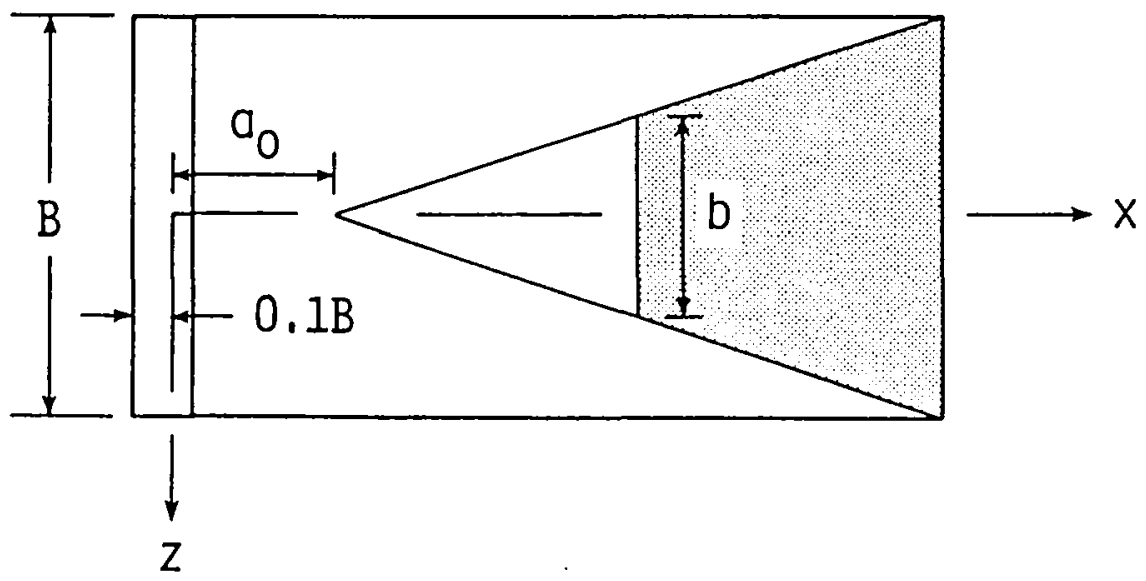

(b) $y=0$ plane.

Figure 5.- Coordinate system used to define dimensions of knife-edge loaded chevron-notched rod and bar specimens. 


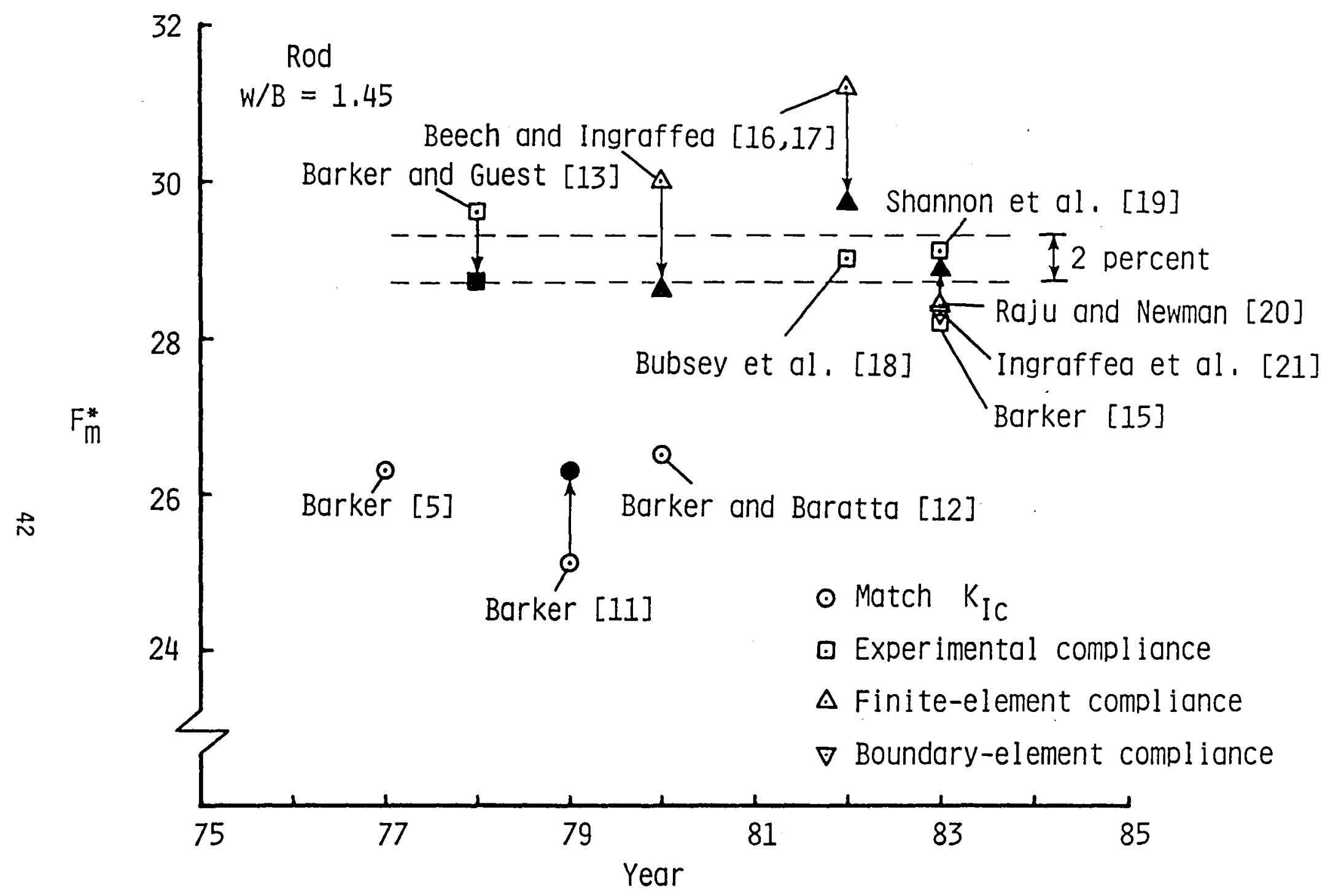

Figure 6.- Comparison of minimum normalized stress-intensity factor for chevron-notched rod. 




Figure 7.- Comparison of distribution of normalized stress-intensity factors along crack front for short chevron-notched rod. 


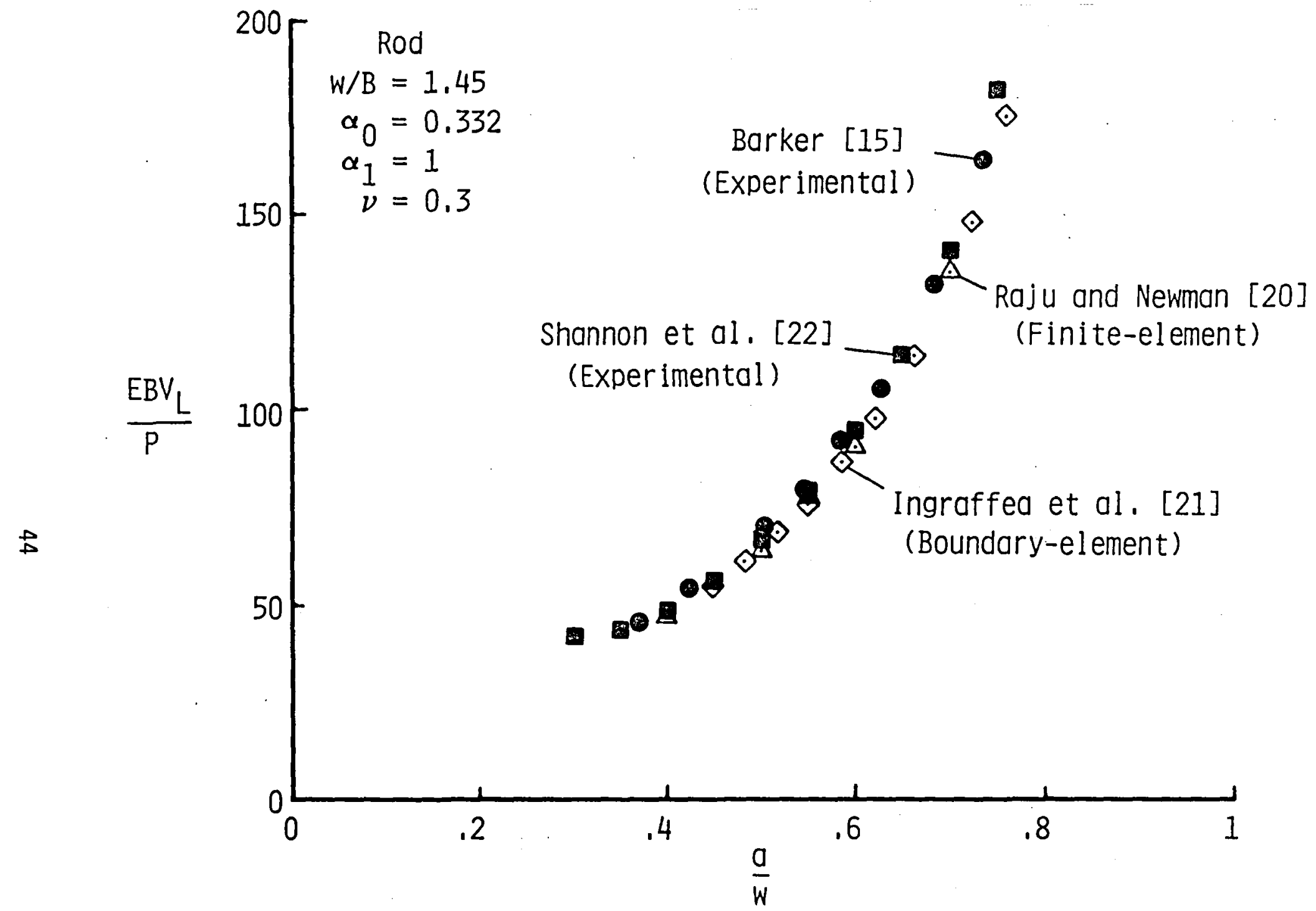

Figure 8.- Comparison of experimental and analytical load-point displacements for short chevron-notched rod. 


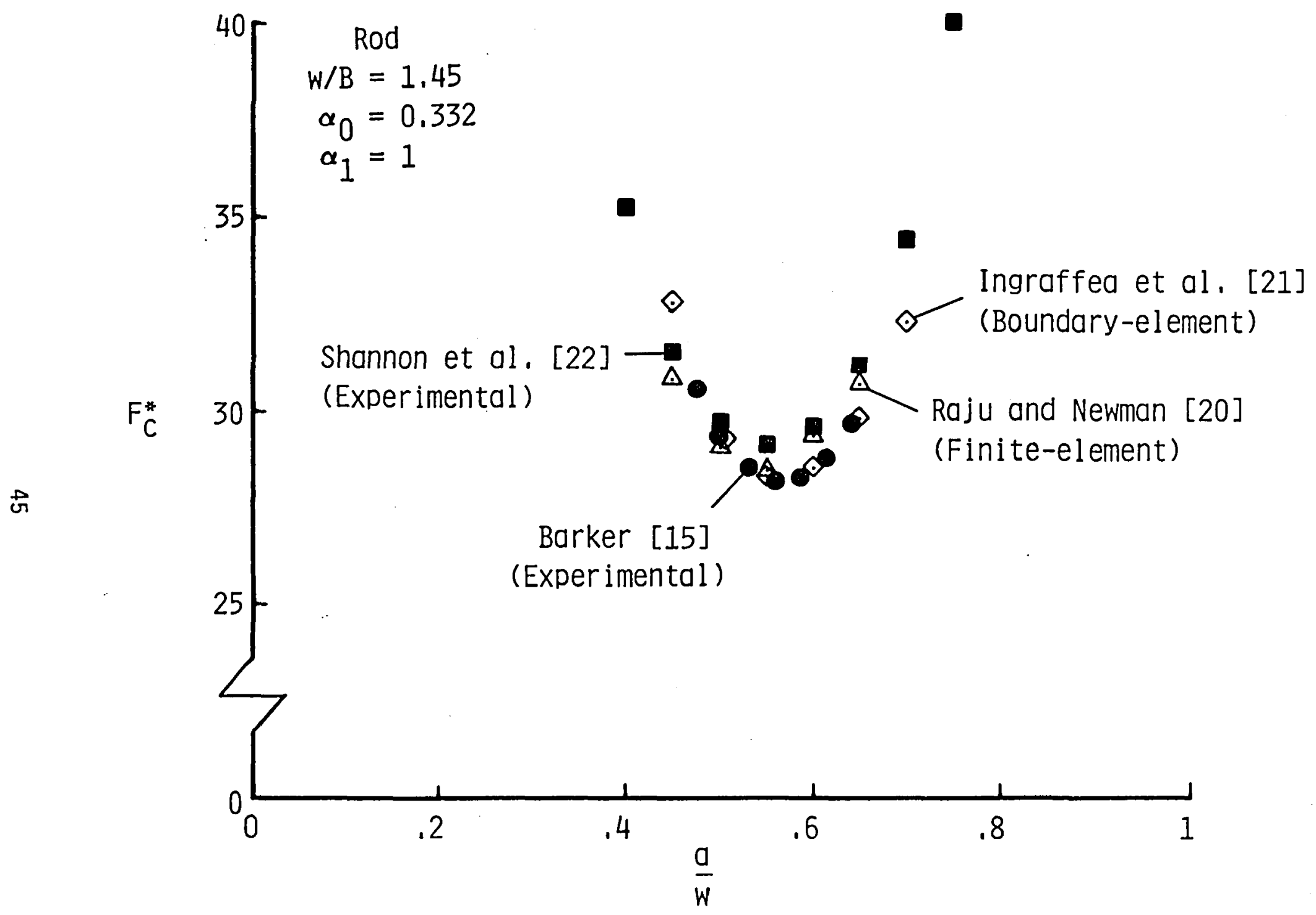

Figure 9.- Comparison of experimental and analytical normalized stress-intensity factors for short chevron-notched rod. 


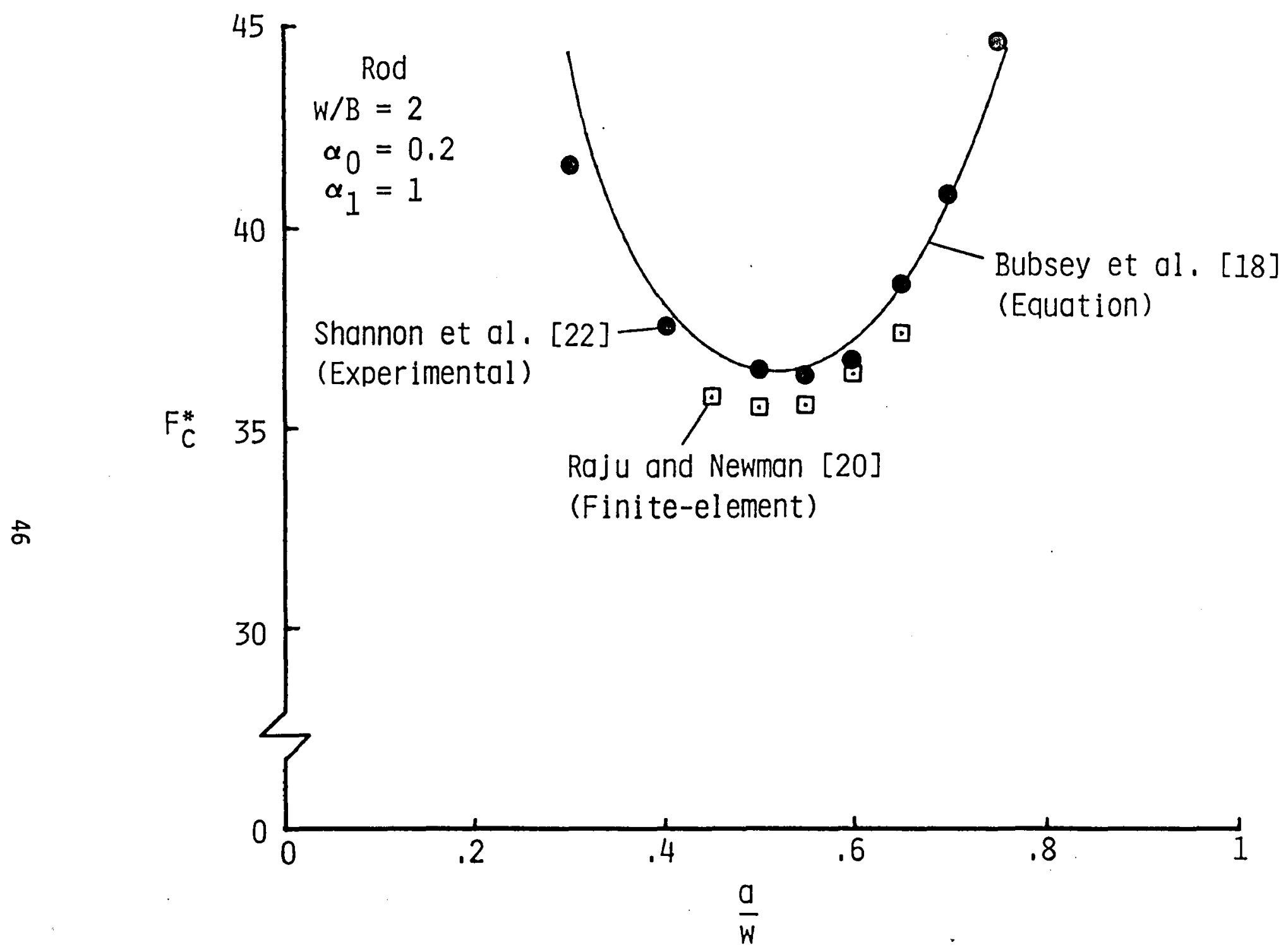

Figure 10.- Comparison of experimental and analytical normalized stress-intensity factors for long chevron-notched rod. 




Figure 11.- Comparison of distribution of normalized stress-intensity factors along crack front for long chevron-notched bar. 


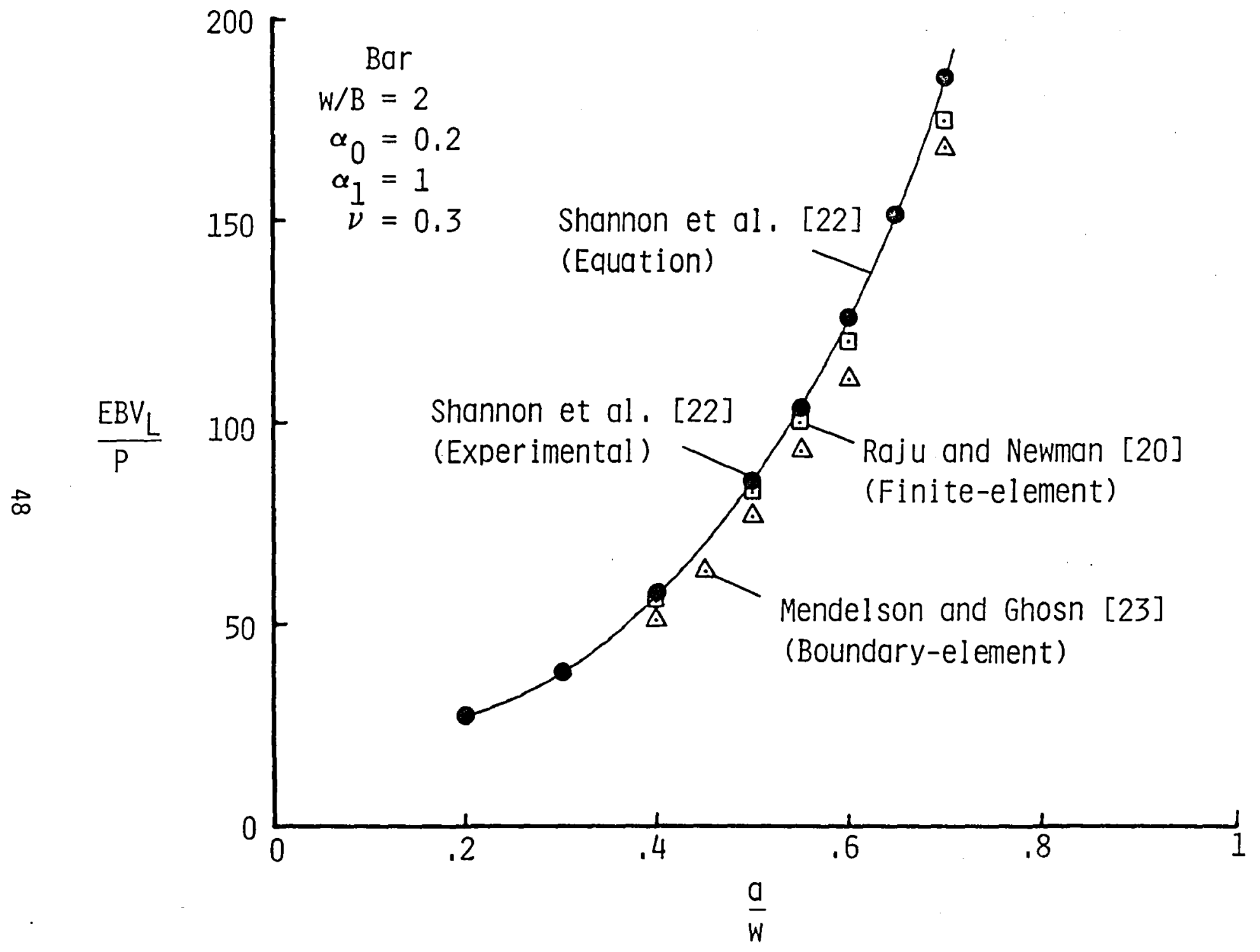

Figure 12.- Comparison of experimental and analytical load-point displacements for long chevron-notched bar. 


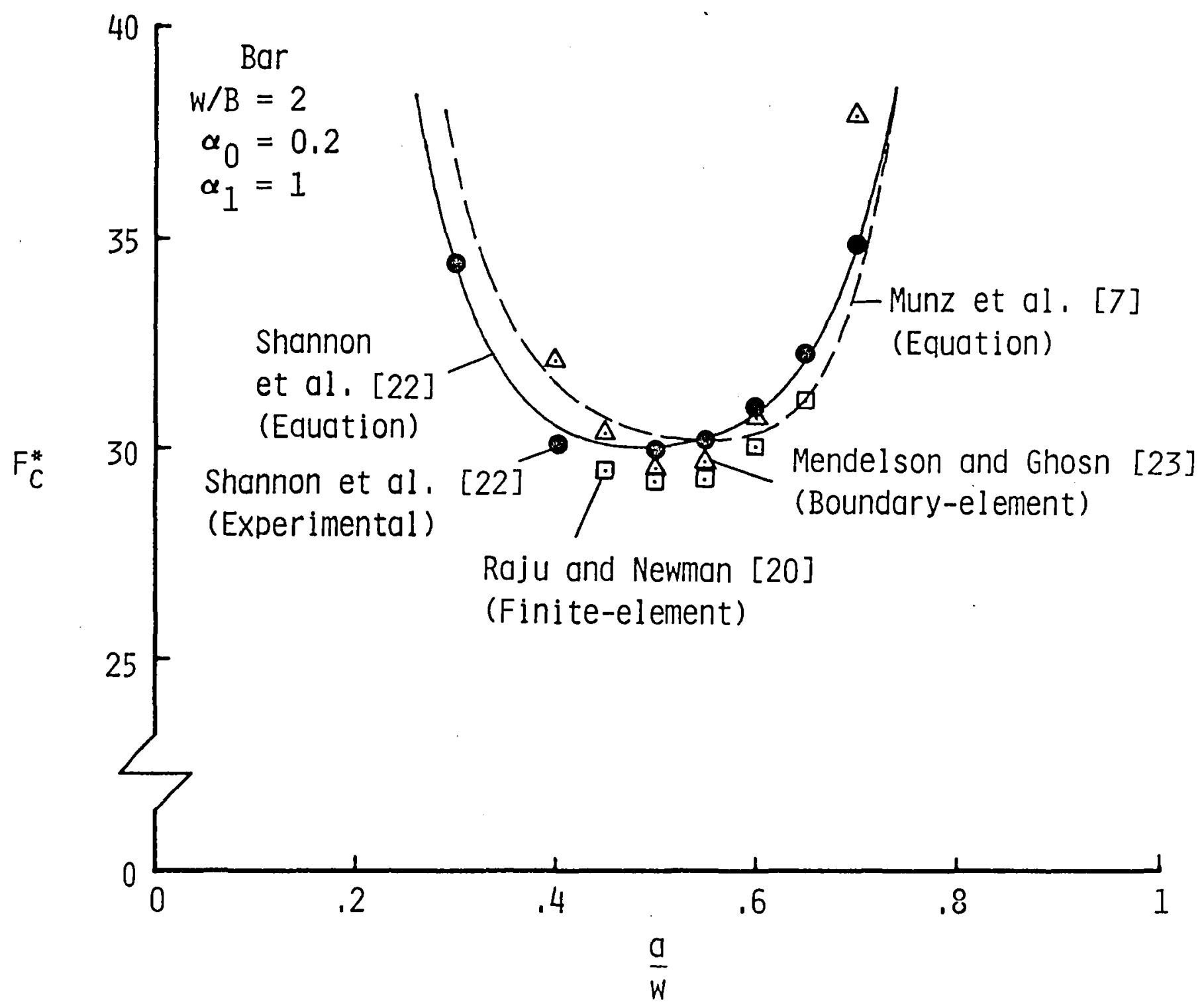

Figure 13.- Comparison of experimental and analytical normalized stress-intensity factors for long chevron-notched bar. 


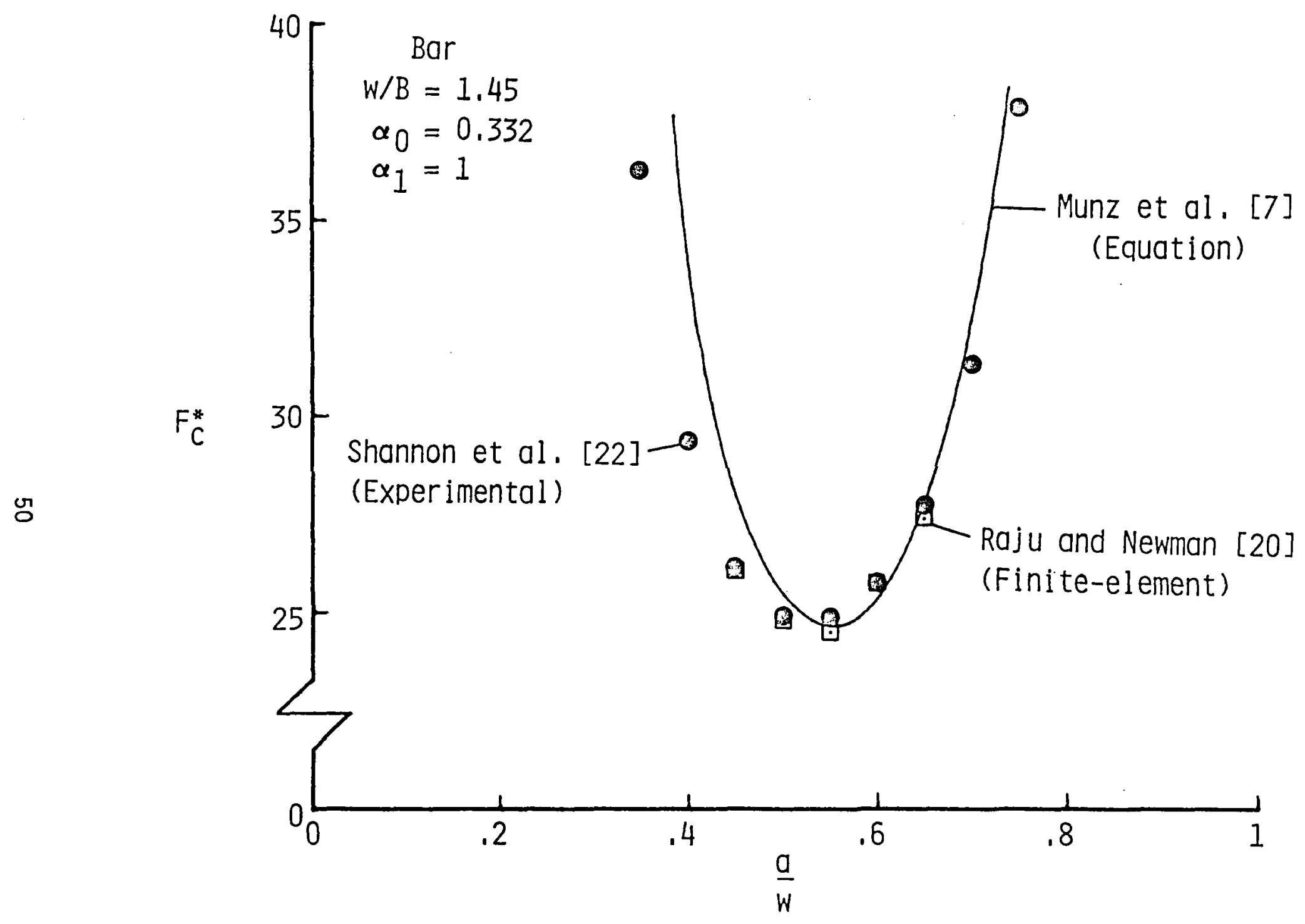

Figure 14.- Comparison of experimental and analytical normalized stress-intensity factors for short chevron-notched bar. 


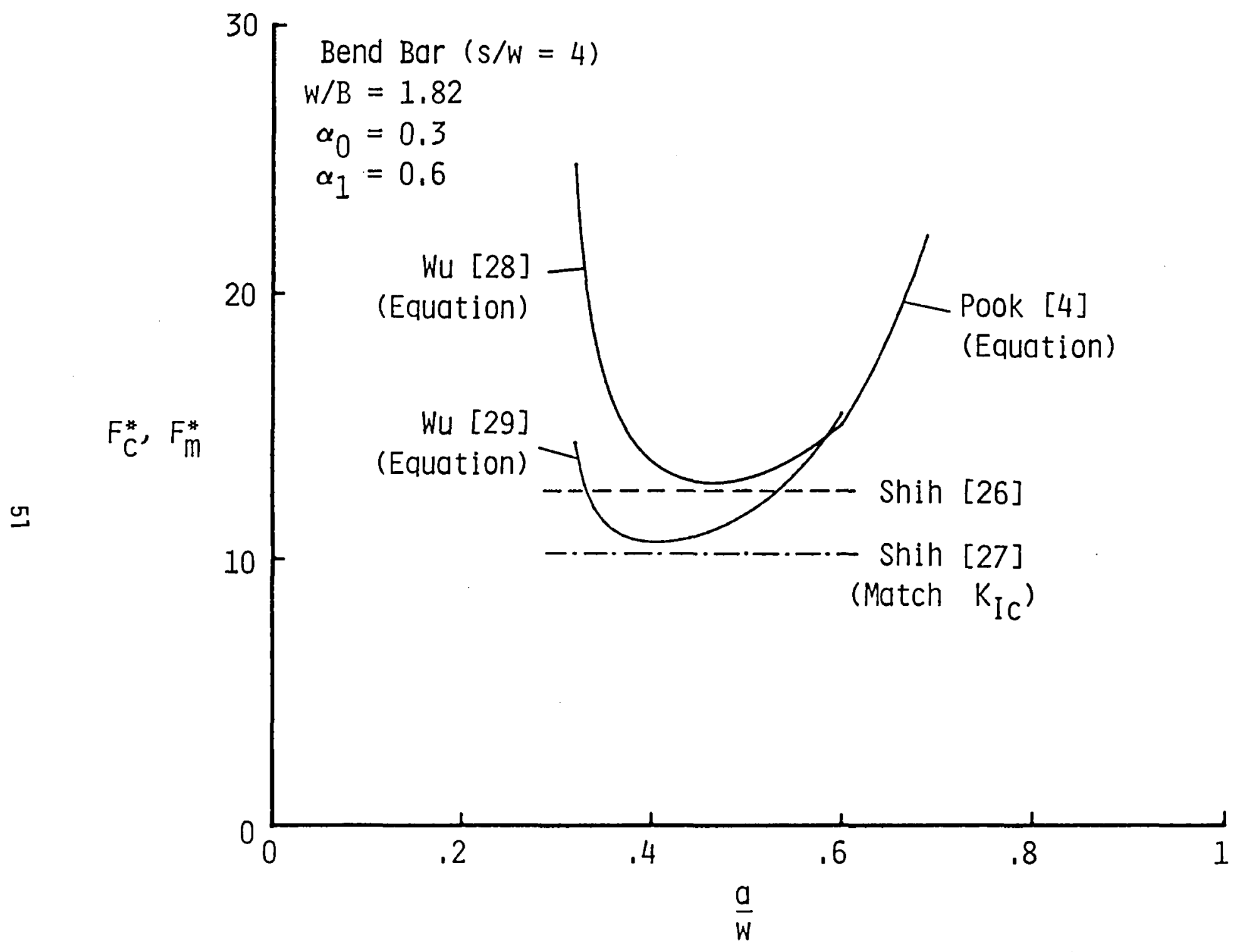

Figure 15.- Comparison of normalized stress-intensity factors for chevron-notched three-point bend bar. 


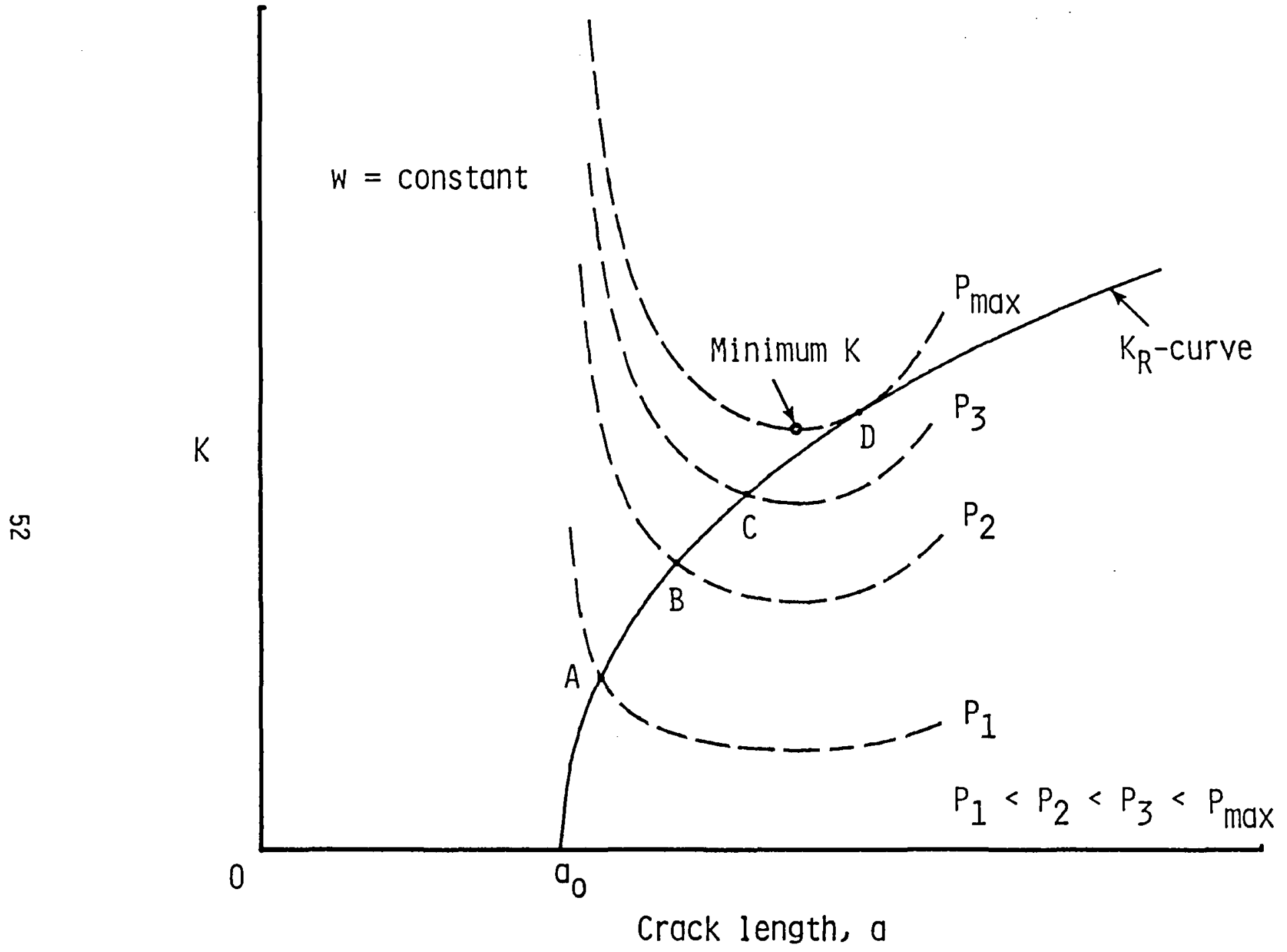

Figure 16.- Fracture of "rising $\mathrm{K}_{\mathrm{R}}$-curve" material using a chevron-notched specimen. 





15. Supplementary Notes

16. Abstract

This paper reviews the historical development of chevron-notched fracture specimens; it also compares stress-intensity factors and load line displacement solutions that have been proposed for some of these specimens. The review covers the original bend-bar configurations up to the present day "short" rod and bar specimens. In particular, the results of a recent "analytical" round robin that was conducted by an ASTM Task Group on Chevron-Notched Specimens are presented.

In the round robin, three institutions calculated stress-intensity factors for either the chevron-notched round-rod or square-bar specimens. These analytical solutions were compared among themselves, and then among the various experimental solutions that have been proposed for these specimens. The experimental and analytical stress-intensity factor solutions that were obtained from the compliance method agreed within 3 percent for both specimens. An assessment of the consensus stressintensity factor (compliance) solution for these specimens is made.

The stress-intensity factor solutions proposed for three- and four-point bend chevron-notched specimens are also reviewed. On the basis of this review, the bendbar configurations need further experimental and analytical calibrations.

17. Key Words (Suggested by Author(s))

Fracture mechanics, stress-intensity factor, cracks, finite-element method, boundaryelement method, crack-opening displacement, chevron-notch specimen
18. Distribution Statement

Unclassifed - Unlimited

Subject Category 39
19. Security Classif. (of this report)

Unclassified
20. Security Classif. (of this page) Unclassified

21. No. of Pages

53
22. Price

A04 

